\title{
Ecology of Architecture
}

\author{
by
}

Mathieu J. Blais

A thesis submitted to

The Faculty of Graduate Studies

in partial fulfillment of

the requirements for the degree of

\section{MASTER OF ARCHITECTURE}

M.ARCH. (Professional)

Carleton University

OTTAWA, Ontario

(September 3, 2008)

(C) copyright

2008, Mathieu J. Blais 
It is the purpose of this thesis to combine disparate parts of this ideologically fragmented period for the profession of architecture under the heading 'Ecology of Architecture'. This philosophy is underscored by the belief that the realm of architecture encompasses much more than what a site plan can show. Without local building traditions, indigenous materials, a dominant vernacular style, how does design etiquette change to appropriately represent the essence of older cities as they evolve into a time of greater choice, greater demand, and greater responsibility? Today, placeless, ubiquitous architecture erodes identity and style hinges primarily upon budgetary girth and fashion. With developments such as Dubai City and that of sprawling exurban, cookie-cutter neighbourhoods, it would seem as though, despite awareness of the current strain on non-renewable resources, a schizophrenic attitude persists in which the desperate need to recognize limitation is being ignored. A redefinition of architectural decorum, one in which environmental, sociological, historical, and economical forces are in agreement, is undeniably overdue. 
Acknowledgements

This study could not have materialized without the committed support and aid of my mother, Elaine Blais, and also that of my advisor, Stephen Fai. A mere thank you seems insufficient. I depart from my academic career with determination, unfettered optimism, and unshakable conviction. 
Abstract

Acknowledgements iii

List of Figures v v

$\begin{array}{ll}\text { Introduction } & 1\end{array}$

Provenance: Motivations for Questioning the Status Quo 5

Living Architecture vs. Dead Architecture: An Architectural Theory of Evolution 15

Weathering: Seeing Through Rhetoric $\quad 22$

Perpetuation Over Preservation: Architecture as Oral History 36

St. Brigid's Church: Design Strategy 56

$\begin{array}{ll}\text { Conclusion } & 71\end{array}$

$\begin{array}{ll}\text { Bibliography } & 75\end{array}$ 
Figure 1: Nickel Tailings, Copper Cliff, Ontario

Pauli, Lori. Manufactured Landscapes: The Photographs of Edward Burtynsky.

Ottawa, Ontario: National Gallery of Canada, 2003 p. 76.

Figure 2: Super Stack, Copper Cliff, Ontario

Figure 3: Google Earth Image of INCO Ltd. property, Copper Cliff, Ontario November, 2006. <http://earth.google.com>

Figure 4: INCO Ltd. Sulphur Dioxide Emissions, Sudbury, Ontario Sudbury Area Risk Assessment (SARA) Group. "Sudbury Area Risk Assessment Final Report - Volume 1 - Chapter 2: History of the Sudbury Smelters." May 2008, July 282008.

$<$ http://www.sudburysoilsstudy.com/EN/media/Volume I/SSS Vol I Chapter $2 \mathrm{Hi}$ storyoftheSudburysmelters FINAL \%20Jan2008.pdf>.

Figure 5: Derelict Villa Savoye, Poissy-sur-Seine, France (1928-31), Le Corbusier Leatherbarrow, David, and Mohsen Mostafavi. On Weathering: The Life of Buildings In Time. Cambridge, Massachusetts: Massachusetts Institute of Technology, 1993 p. 8.

Figure 6: Villa Schwob, La Chaux-de-Fonds, Switzerland (1916), Le Corbusier Curtis, William J.R. Modern Architecture Since 1900. New York, New York: Phaidon Press Inc., 2003, p.167.

Figure 7: Baker House, MIT, Cambridge (1947-8), Alvar Aalto. September 2005, after restoration. North façade

Mathieu Blais, September 2005.

Figure 8: Baker House, South façade Mathieu Blais, September 2005.

Figure 9: Theatre of Marcellus, Rome (13-11 BC), Plan Sear, Frank. Roman Theatres: An Architectural Study. New York, New York: Oxford University Press Inc., 2006, p. 135.

Figure 10: Theatre of Marcellus, Rome, present-day Hines, Thomas G. "The Ancient Theatre Archive." Whitman College, 2003, June 29 2008. <http://www. whitman.edu/theatre/theatretour/marcellus/marcellus.htm>. 
Figure 11: Lord Elgin Hotel, Ottawa, Ontario (1941). South block addition completed 2002. Example of conjunctive theory.

Mathieu Blais, May 282008.

Figure 12: Royal Ontario Museum, Toronto, Ontario (1914). Third expansion by architect Daniel Libeskind and Bregman + Hamann Architects, projected to be complete by 2010. Example of disjunctive theory.

Hsu, Ben. Webshots Travel. September 29 2007, June 292008.

$<$ http://travel. webshots.com/photo/2413961080101453251EkbtHp?vhost=travel>.

Figure 13: Demolotion of Napoleonic stair

Olsberg, Nicholas et al. Carlo Scarpa Architect: Intervening With History. New York, New York: The Monacelli Press Inc., 1999, p. 231.

Figure 14: Castelvecchio Museum, Verona, Italy (1959-73). Area of excised bay of gallery wing.

Mathieu Blais, February 2005.

Figure 15: Detail studies demonstrating evolution of Cangrande statue's stand and configuration.

Photo: Mathieu Blais, February 2005.

Sketches: Olsberg, Nicholas et al. Carlo Scarpa Architect: Intervening With History. New York, New York: The Monacelli Press Inc., 1999, p. 77, 79, 80, 82, 83.

Figure 16: Waisenhausplatz

Mathieu Blais, January 2007.

Figure 17: Closed configuration

Mathieu Blais, March 2007.

Figure 18: Open configuration

Mathieu Blais, March 2007.

Figure 19: St. Brigid's Church, south-east corner Mathieu Blais, October 2007.

Figure 20: Aerial view of ByWard Market in area of St. Brigid's Church August, 2008. <http://earth.google.com>

Figure 21: View of new façade on north side Mathieu Blais, August 2008.

Figure 22: View of new façade on south side Mathieu Blais, August 2008. 
Figure 23: View of new façade on east side Mathieu Blais, August 2008.

Figure 24: Clockwise from bottom left: ground floor plan, second floor plan, third floor plan. Plans are not to scale Mathieu Blais, August 2008.

Figure 25: Clockwise from bottom left: longitudinal section looking toward east, cross section looking toward south, cross section looking toward north Mathieu Blais, August 2008.

Figure 26: Clockwise from bottom left: north elevation, south elevation, east elevation

Mathieu Blais, August 2008.

Figure 27: Operations on existing. From left to right: window modified to become a door, elevator installed in place of altarpiece, structural steel skeleton framing existing column.

Mathieu Blais, August 2008

Figure 28: A stretch of Rideau St., Ottawa, Ontario. The condo tower (right) attempts to blend in to its historic setting.

Mathieu Blais, June 252008. 
The profession of architecture is in a compromising position. It has succumbed to the pressures of the globalism. Buildings, like many of today's goods, have become consumables. The phenomenon of disposability without accountability has become manifest in the most polluting of objects: the buildings we inhabit. This attitude is the result of the commonly held perception that we are entitled to a seemingly unlimited supply of resources. Conversely, historical cities that resisted the Industrial Age are in a state of inalterability but have imperiled their futures by their dependence on tourism and their unwillingness to change. Such cities would appear to be in a 'lose-lose' situation, as the uncertainty of change poses a threat to their 'raison-d'être'. In two thousand years, what legacy will either, historic or more contemporary cities, bequeath? What strategies, historical or contemporary, could be brought to bear now to ensure an architecture whose goal is to "augment reality" ? I argue that there is a fulcrum between immutable oldness and shoddy newness. Finding the elusive balancing point between the two depends upon discovering the broader role of architecture on a metropolitan scale: like an ecological framework, a city functions via a complicated network of interrelationships involving organisms and the built environment. In an 'Ecology of Architecture', this ever-fluctuating web of interdependent elements includes

${ }^{1}$ David Leatherbarrow and Mohsen Mostafavi, On Weathering: The Life of Buildings In Time (Cambridge, Massachusetts: Massachusetts Institute of Technology, 1993) 97. 
everything from the city's physical makeup and configuration to its economic, environmental, and societal wellbeing.

What we remember of cities are those things that are particular to them. A city's identity is largely rooted in its architecture. Just as a forest is erased by clear cutting, so too is a city erased when it succumbs to insensitive development. A forest's ecological balance amounts to much more than the mere presence of old trees. It is the complex network of interactions of organisms within their environment that maintains equilibrium. The forest's history is written in the generations of layers of vegetative strata that make up its floor. A similar record can be discerned in the components of a city.

Of the strata that comprise the City of Ottawa's historical floor, the ByWard Market area constitutes one of the most significant. Its character and story are legible in the façades of its weathered masonry buildings. Contemporary commercial signage stands in marked contrast to the old buildings in the Market. This area is imbued with a sense of memory. A relatively recent phenomenon is the intrusion of incongruous condo towers into the historic fabric. Older buildings are felled and supplanted by these hulking towers leaving neighbouring homes awkwardly juxtaposed and shadowed. This excision of portions of the fabric is a problem exacerbated by the interruptions caused by the towers which are usually accompanied by cumbersome parking structures. The consequences are evident and irrevocable. A new history is being written that is ignorant of the Market's 
provenance and evolution. The result for the historical character of the Market is death by attrition.

The remaining old buildings must be allowed to continue their discourse within their rightful domain and should be allowed to resist the persistent pressure of placelessness. They mustn't become precious objects frozen in time but must continue to live and speak in new and different incarnations. This principle is not without precedent in the Market. The majority of present commercial enterprises operate out of old homes and apartment tenements. Creaking stairs, worn banisters, and uneven floors are typical of the shopping experience in the Market and contribute greatly to the place's charm.

It is in this spirit that St. Brigid's Church, now decommissioned, will fulfill its new role and perpetuate its history. In designing under the premise that a city is itself an ecology with its own unique set of complex interactions and relationships, a more sensitive solution than razing buildings may be devised which would allow Ottawa to retain a part of its history, to remain recognizable, to maintain a gradient in the chronology of what comprises its built environment. In an 'Ecology of Architecture', balance is maintained by considering those elements which are largely ignored in contemporary building practice, namely: the environmental impact of all new construction, the historical context of each individual project, the capacity of a well-weathered building to renew its finish over time and to directly transmit information from the time of its inception, the source for civic pride and the sense of belonging to a place, the benefits of lending new uses to so-called historic 
buildings, the importance of an architect understanding the meaningfulness of place as a reflection of his/her understanding and acceptance of his/her own provenance. This implies a much more comprehensive approach which would certainly be at odds with the current system for producing buildings. Consideration is sometimes given to one or a few of these factors but it is now imperative that all of these factors come into play, given the constraints on resources that are soon to become apparent as worldwide, humans suffer a 'crude awakening' with the end of the fossil fuel age. 
Provenance: Motivations for Questioning the Status Quo

The city in which I grew up: Sudbury, Ontario, is reputedly one of the most polluted in the world. I recall, as a child, standing on the barren hills near my grandparents' house and seeing the horizon completely unhindered by any type of vegetation. My mother recounts that as a child she would run outside when the wind was blowing in a certain direction to drape wet burlap over the vegetables in the garden so that the sulfur clouds wouldn't burn them. Incomparable mineral wealth made Sudbury an unprecedented source for nickel, iron ore, copper, zinc cadmium and a number of other highly prized minerals on the global market. The exploitation of the region's considerable resources for more than one hundred and

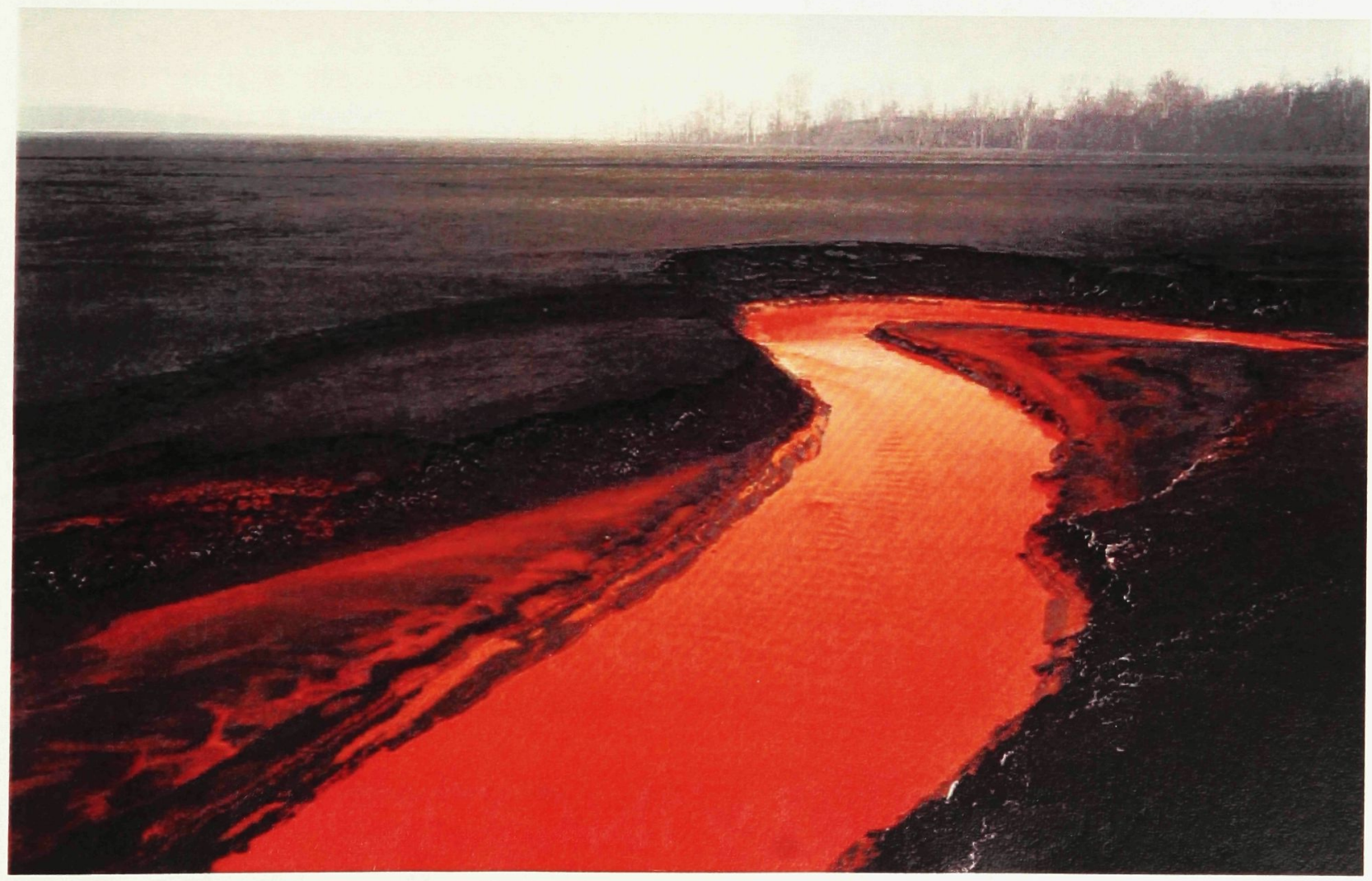

Fig. 1 - Nickel Tailings, Copper Cliff, Ontario 
twenty years has had a devastating effect on the soil, the water, the air and last, but not least, the residents of the Sudbury basin. The construction of a much taller and more efficient smelting tower, the Super Stack, in Copper Cliff in 1972 and the emergence of environmental groups such as the Cooperative Freshwater Ecology Unit (CFEU) (1989) are some of the factors which set in motion a significant re-greening initiative in Sudbury. However, even today, the landscape surrounding the International Nickel Company's (INCO) primary smelting site in Copper Cliff remains largely denuded and desolate. An aerial view of the site reveals, to this day, disturbingly colourful tailings ponds, vast slag heaps, and piles of

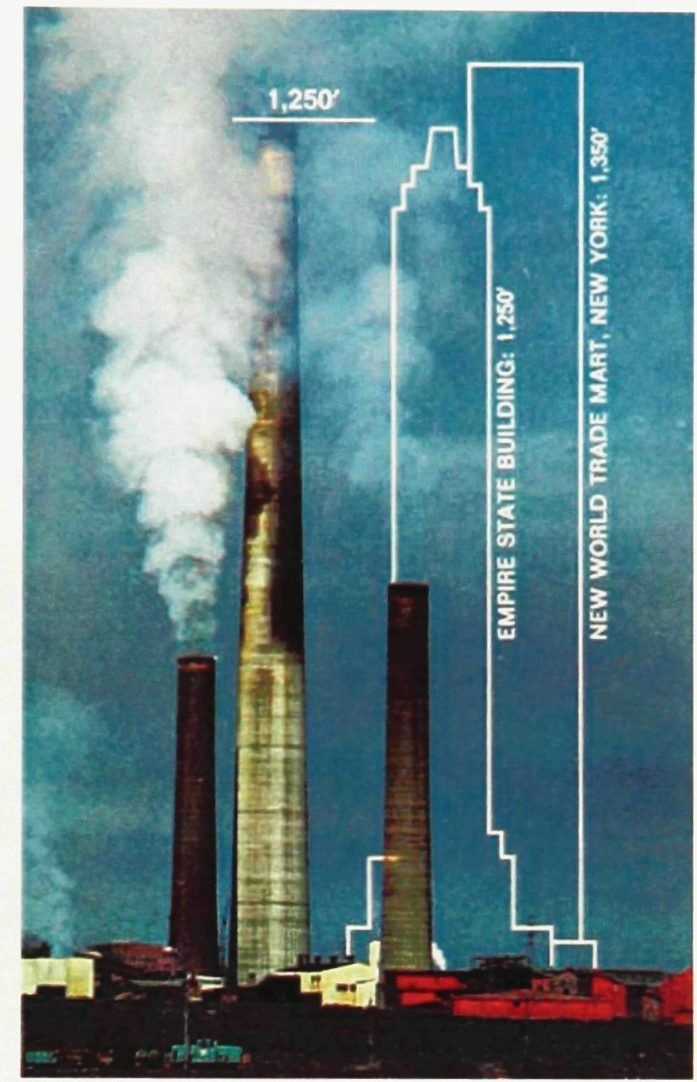

Fig. 2 - Super Stack, Copper Cliff, Ontario miscellaneous industrial waste concentrically distributed around the Super Stack in dangerously close proximity to people's dwellings. For more than a century the extraction of nickel and other base metals and the resulting huge profits generated by these activities have been valued above the health and wellbeing of Sudbury residents. It isn't hyperbole to theorize that INCO Ltd. and Falconbridge Ltd. mining companies have perpetrated a serious crime against the citizens of the Sudbury area. In 1974, two years after the construction of the Super Stack, a secret document "titled 'The Sudbury Pollution Problem: Socio-Economic 
Background' concluded the damage from emissions would cost Sudbury approximately $\$ 465,850,000$ to human health, vegetation and property values annually. Historically, there have been no prosecutions under applicable environmental legislation, and from 1924-1970, there was a curtailment of a citizen's right to sue for any damages, and there has been a lack of government sponsored research on the damage caused by the copper-nickel smelters." In his book Small is Beautiful: Economics as if People Mattered, E.F. Schumacher explains: ${ }^{3}$

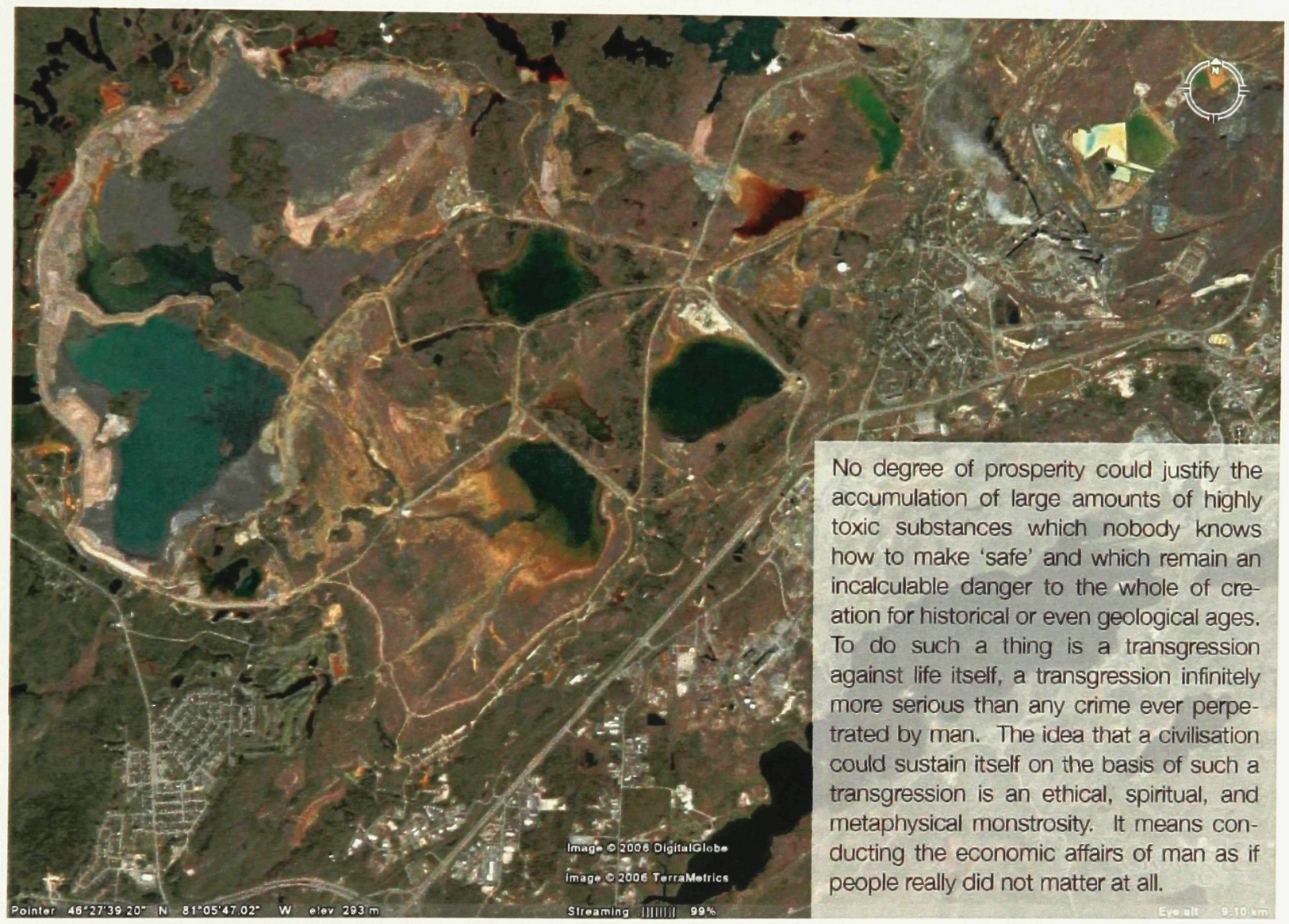

Fig. 3 - Google Earth Image of INCO Ltd. property, Copper Cliff, Ontario

${ }^{2}$ Bill Bradley, "Digging Through the Sudbury Soils Study," Northern Life 29 May, 2008: 3.

${ }^{3}$ E.F. Schumacher, Small is Beautiful: Economics as if People Mattered (New York: Harper \& Row, Publishers, 1973) 137. 
If Schumacher's opinion were law, as it rightfully should be, these corporations, as well as all others who have committed such crimes, would be found guilty. It is certainly unlawful for a person to kill another person. Is it not the same when the process is a slow poisoning taking place over a number of years and affecting a large number of people? The fact that wealthy corporations are permitted to infringe the rights of unsuspecting citizens in the name of job creation and profit proves that our current economic system tacitly fosters the notion that the powerful and rich operate above the laws that govern us all which is, as Schumacher put it, 'a monstrosity'.

Biologists refer to Sudbury as a 'test-tube ecology'. For as long as there's been mining activity in Sudbury, its ecology has been subjected to a harsh science experiment in which all vegetative life was chemically withered away. In attempting to aid Mother Nature in reversing the ill effects of all this polluting, much has been

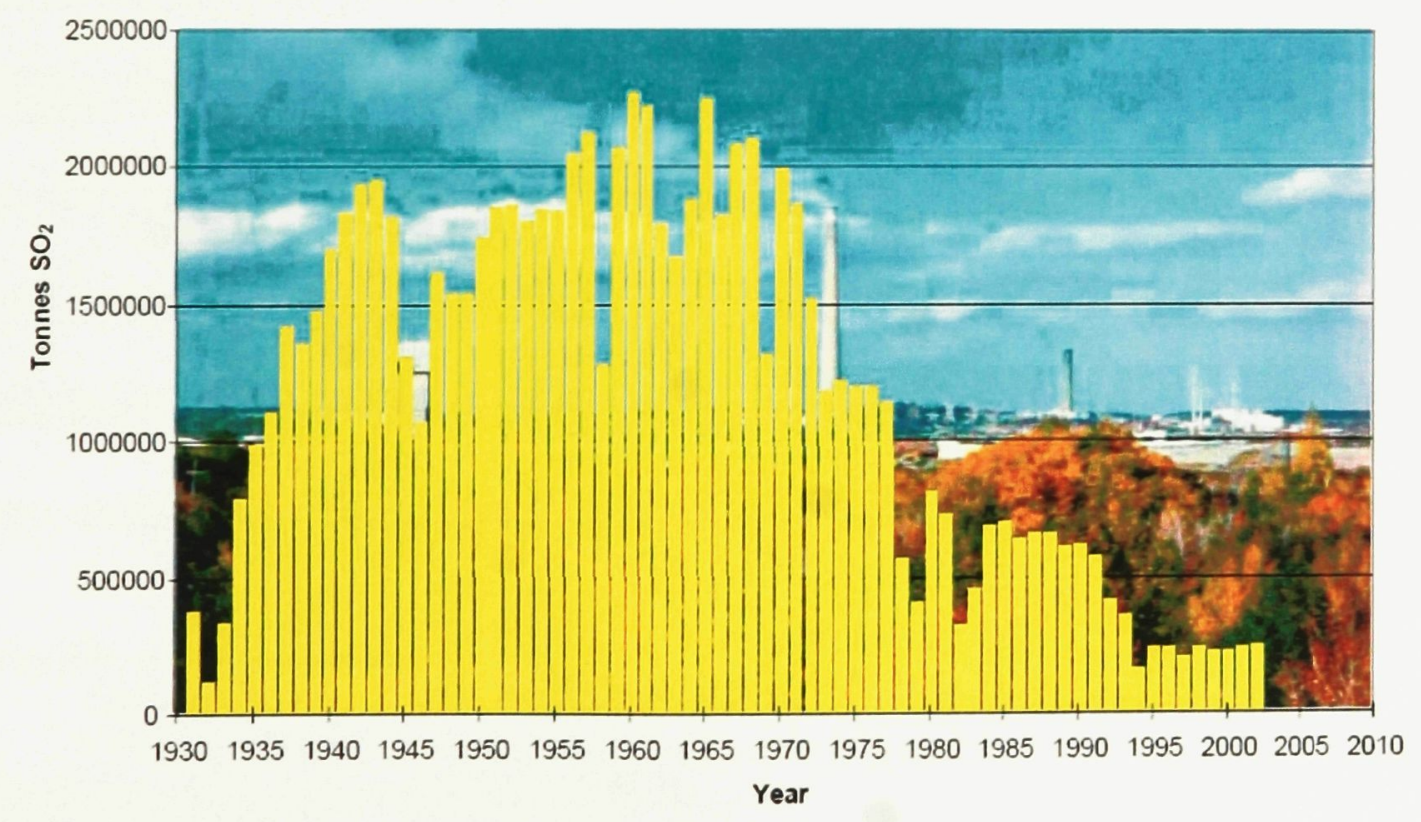

Fig 4. - INCO Ltd. Sulphur Dioxide Emissions, Sudbury, Ontario. 
learned about the resiliency of the resident flora. Documentation of this healing process ensures that the extent of the damage that was done is acknowledged and properly understood. The Sudbury Soils Study was released in May 2008. The $\$ 10$ million, 7 year long study funded by Vale INCO and Xstrata Nickel (formerly INCO Ltd. and Falconbridge Ltd. respectively), the very companies responsible for more than a century's worth of environmental damage, had as its mandate to evaluate "the human and ecological risks associated to six chemicals of concern, including nickel and lead." ${ }^{4}$ Lead was found to be the most abundant of any of the metals but the risk of exposure to lead was described as 'minimal'. Strangely, the results of the study revealed that the major source for exposure to lead for residents is in supermarket food and that the overall "levels of lead detected in the soil in the Sudbury area are similar to levels found in other older urban communities in Ontario that have no industrial sources." ${ }^{5}$ The results have been met with skepticism by Sudbury residents but the Mayor John Rodriguez insists that the study "has been very transparent." The study is described as "one of the largest and most comprehensive of its kind in North America." ${ }^{7}$ Despite being under the relentless shadow of the Super Stack, Sudbury has managed, to a certain extent, to bounce back. Historically, neither the environment nor architecture were ever salient issues

\footnotetext{
${ }^{4}$ Bradley, 3.

5 "Human Health Risk Assessment Results," May 2008. Sudbury Soils Study. 28 July 2008. $<$ http://www.sudburysoilsstudy.com/EN/media/handouts/SSS HHRA_ENG.pdf>.

${ }^{6}$ Bradley, 3.

7 “Human Health Risk Assessment Results," May 2008. Sudbury Soils Study. 28 July 2008. $<$ http://www.sudburysoilsstudy.com/EN/media/handouts/SSS HHRA ENG.pdf>.
} 
in this city. The end of the twentieth century with its accompanying emphasis on restoring the environment along with the innovations in the mining and smelting sectors which have to some extent impacted the landscape and the thinking of the residents of the Sudbury area give rise to hope for a more balanced outlook in the future. Recently, a project has been proposed at Laurentian University to replace the CFEU's former headquarters with a new environmental building that will be called the 'Living With Lakes Centre'. A joint venture between J.L. Richards in Sudbury and Busby, Perkins, Will Architects, one of Canada's leading firms specializing in green, energy-efficient design, is expected to yield a biological research facility unparalleled in its ability to generate its own power, collect its own water, and treat its own waste to minimize its total negative ecological effect. The building and site are expected to feature wind turbines, solar thermal collector tubes, on-site composting, and a green roof as natural means of preserving nonrenewable energy. It is also important to note that these objectives would need to be met within the confines of what can be considered a strict budget by conventional building standards. In an early design meeting that I was able to attend, Peter Busby explained that, for such a research facility with such specific needs, the building design and regulating systems were going to have to be coordinated in a way that would yield maximized energy efficiency to a level never before achieved in any of his buildings. For such a building to exist in this place signals a dramatic shift in ideology. Very little, if any consideration has been given to preserving any of Sudbury's architectural heritage. Some of the oldest and most 
imposing structures: the downtown train station, Old City Hall, the College SacreCoeur have been unceremoniously obliterated or abandoned. New construction is prosaic and utilitarian. However, there seems to be a new spirit abroad in certain influential sectors of the community and some are calling for action to preserve or repurpose what is left of past buildings and to exercise some forethought with regard to future construction. If attitudes can change in Sudbury, a place whose name was once used as a unit of measure for pollution, then there certainly is hope that ecofriendly approaches to architecture can effectuate change through the promotion of environmentally conscious design.

My experience working in Sudbury and learning its history as part of my job as a summer intern was invaluable in shaping my ideas about buildings. This place's story is one worthy of recognition. I take any opportunity I can to listen to my grandfather, Ugo Comacchio, the son of Italian immigrants, tell tales from inside the smelter and what it was like to be alive while the city was in a rapid state of flux. His perspective tempers some of my negative feelings about the havoc caused by mining in Sudbury because INCO represented his livelihood. Both of my grandfathers worked for INCO to provide for their families. The fact remains that without INCO, there would be no Sudbury.

My connection to this place affects me on many levels. Consequently, it has had a pronounced influence on my life and my choice of profession. I am fascinated by how cities function and how they don't. In studying architecture, l've had the opportunity to visit many cities in North America and abroad and to 
observe the various ways that they achieve economic stability. I'm particularly interested in those cities which succeed in prospering while, at the same time maintaining their ecological balance. I'm of the opinion that a concern for the environment should be at the forefront of the thinking of any practicing architect today. The built environment accounts for forty percent of environmental impact making it the largest single source affecting global warming. ${ }^{8}$ This startling statistic, for someone with my provenance, cannot be disregarded.

In his book Heat: How to Stop the Planet from Burning, George Monbiot points the finger at Canadians and reveals that our irresponsible habits create on average 19.05 tonnes of carbon dioxide emissions per capita per year, "just 50 kilos less than the Australians and a tonne less than the Americans." ${ }^{" 1}$ it is his purpose in this book to find realistic ways of cutting carbon emissions by $90 \%$. In the chapter 'Our Leaky Homes', Monbiot meticulously probes the causes of inefficiency which are, unsurprisingly, largely preventable but due to the fact that we aren't obliged to take notice of our energy consumption, we remain blissfully ignorant of the repercussions of our unfettered use of fossil fuels and their byproducts.

The number one culprit is the building envelope. Whether part of an old, inefficient house or a new construction, the incentives simply aren't in place to force homeowners, landlords, or developers to build or renovate at a higher standard.

\footnotetext{
${ }^{8}$ Ed Lowans, "Sustainable Architecture," Carleton University, Ottawa, Ontario. February 2008.

${ }^{9}$ George Monbiot, Heat: How To Stop The Planet From Burning (Canada: Doubleday Canada, 2006) ix.
} 
Monbiot's study is based on homes in the UK but it isn't difficult to extrapolate that the same scenarios are transpiring here in Canada. Most homes in the UK are older than most Canadian homes and don't retain heat as well. In Monbiot's words: "Our homes act as warm air tunnels: they keep us warm almost incidentally, as the heat pours past us and into the street."10 In renovating his own home, Monbiot became aware of the full impact of poor building standards. A property developer had renovated the house for $£ 60,000$ (\$116,000 CA) before Monbiot's family moved in. If the developer had spent an extra $£ 1,000$ insulating the walls properly, he would've saved Monbiot half the cost of his energy bills. Instead, to reverse the shoddy workmanship would result in an additional expenditure of $£ 20,000(\$ 31,800 \mathrm{CA})$ that would essentially add nothing to the value of the house thus rendering the effort unfeasible. Whatever few weak building regulations there were for the developer to follow were ignored and, subsequently, not enforced. In regards to new construction, which should logically be much simpler to get right, builders are virtually absolved from any obligation in satisfying even a minimum for energy efficiency. 'Approved' inspectors from the private sector, fearful of seeming too strict, grant certificates of compliance to buildings that rightfully should fail. ${ }^{11}$ Consequently, builders have nothing to fear when it comes to legal prosecution from insurers in the matter of energy efficiency either. We're encouraged to fill our homes with 'Energy Star' appliances that economize energy but this seems trivial when compared to the gross savings that would be had if our homes were built to a

\footnotetext{
${ }^{10}$ Monbiot, 65.

${ }^{11}$ Monbiot, 65.
} 
maximum standard.

Anything short of these ameliorations will mean that we must instead revisit the methods of producing the energy that our buildings employ, this being the much more challenging alternative especially when it comes to re-invigorating or repurposing older buildings. Environmental impact is one factor in developing an 'Ecology of Architecture' and is one dependent upon rigorous analysis of the basic functioning of buildings. Old or new, if buildings are not put together properly in the first place, if the basic fundamentals of architecture have been ignored, then the task is made all the more difficult. One possible remedy may be for the profession of architecture to burrow its way into the political arena and demand that more stringent legislation be put into action. With such comprehensive initiatives as the Subury Soils Study being undertaken, it isn't a stretch to consider how such a study geared toward the environmental and economic impact of our energyintensive structures could form the basis for a new set of guidelines for construction and renovation. Surely, the preservation of non-renewable energy through environmentally sound building practices is a task as worthy as that of minimizing the impacts of industrial pollution. 
Living Architecture vs. Dead Architecture: An Architectural Theory of Evolution

My academic architectural experience has not yielded clear answers to questions about how exactly to do architecture; specifically, questions regarding techniques for the generation of ideas and concepts, and the best design strategies to employ and how to represent them. A smorgasbord of options are at the students' disposal and it is for us to judge which are the most relevant to communicate our ideas. I have never felt pressured into believing that one method of conceiving architecture is necessarily superior to others. I have stood in the soft light entering through the apertures inside the Chapel of Ronchamp and I have felt the enormity of the Duomo. I have experienced the serenity of bathing in the Thermal Baths in Vals while dreamily gazing out toward the Swiss Alps. I have read philosophy, theory, and criticism of various types of architecture in different historical periods. An education in architecture is not obtained by merely attending class and making the grade. An architect's education is the cumulative outlook formulated over time determined by personal experience and the influence left by passionate professors and lecturers and the fleeting opinions exchanged in conversation with one's peers. Occasionally, something clicks and, slowly and almost imperceptibly, that gelatinous, piecemeal mass of accumulated knowledge solidifies and a recognizable voice emerges.

So I suppose it's normal not to have immediately been struck by my experience living in Europe. From January until April in 2007, I worked as a Masters student at Progr Centre for Cultural Production in Bern, the capital of Switzerland. 
It is the slow infiltration of the facets of this experience into my subconscious which provided the stimulus for this thesis topic. I began to draw parallels between Bern and the capital city in which l've lived as a student: Ottawa. There were several obvious differences namely attitudes toward preservation of buildings deemed historic and the degree of involvement of the public at large in the decision process regarding proposals for new construction. It is in comparing the Old World to the New World, specifically their architectural histories and attitudes toward preservation and contemporary expression through design, which gave rise to a number of questions.

Regarding the Ecology of Architecture, which city seems more open to the idea of a fluid history, meaning a mindfulness of the past in conceiving a contribution for tomorrow? It can be argued that the historic capital city of Bern is, in a word, stagnant. Its history acts very much like a straitjacket: constrictive, confining, and unable to accommodate anything new. Since a conflagration in 1405 razed Old Bern to the ground, a densely rebuilt agglutination of beige sandstone buildings has immutably and uniformly stood in situ virtually as it was then. It has uncannily persevered as this incarnation into the modern day which has merited the tiny city the designation 'World Heritage City'. As a consequence of this designation, Bern is a city now in stasis. The role of architecture has become the preservation of the existing fabric and the mitigation of the impacts of necessary contemporary interventions. For example, the old buildings near the water's edge have been replaced by sanitized facsimiles, designed using modern 
means for handling moisture infiltration, but otherwise indistinguishable from their predecessors. The largest upgrades, however, have been more dependent upon feats of engineering rather than architectural planning including huge infrastructural undertakings for modern transportation (buses, trams), modern bridges to link the northern, southern, and eastern banks of the peninsula to the mainland modern portions of Bern, and extensive underground parking structures. The extremely hilly topography on the peninsula accounts for some architectural variability but what comprises the historical fabric is, largely, stultified. With zero gradient for diversity (cultural, ethnic or architectural), historical Bern is itself a citywide museum frozen in time, intolerant of change and creatively stunted. It is a life-size, functional movie set. It is, therefore, inhospitable ground for imaginatively fertile design.

Ottawa is a city steadily undergoing change but such change, as it pertains to its history, cannot be described as 'fluid'. Insensitive toward the past, ignorant of the future, the preeminence of shoddy development in the nation's capital has become alarmingly conspicuous. Ottawa, a North American city of much newer vintage, that grew and matured at the time of the Industrial Revolution, has evolved much differently than Bern. In 1832, burgeoning growth was fueled by the timber industry and the opportunities for trade afforded by the newly constructed Rideau Canal. Today, in addition to being the nation's political center, Ottawa prizes its reputation as a center for the 'high-tech' and 'bio-tech' sectors. ${ }^{12}$ The pressures of modernity provided far different motivations for development in Ottawa than they

12 Timothy A. Gibson and Mark Lowes, Urban Communication: Production, Text, Context (Lanham, Maryland: Rowman \& Littlefield Publishers, Inc., 2007) 132. 
had in the fortified city of Bern, which, at the time it was built, was situated on a peninsula as defense against aggressors. Ottawa, unlike Old Bern, was not bounded in the same way. Proximity to the Ottawa River was a primary siting issue and its virtually unbounded development continues to this day infringing upon the boundaries of the Greenbelt from all directions. ${ }^{13}$

Bern and Ottawa represent two extremes in regards to identity: the former is entrenched in tradition, the latter struggles to establish itself as a recognizable capital city in absence of its history. In Swtizerland In Perspective, Janet Eve Hilowitz explains that Swiss society fosters the idea that "continuity predominates over change."14 Political power is fragmented through several groups which are organized hierarchically in descending order of importance as follows: the national state, the twenty-six cantonal divisions (including the canton of Bern), municipalities and communes, interest groups and associations. ${ }^{15}$ The educational systems, which are cantonal rather than federal, stream youngsters into apprenticeship oriented studies over occupational or professional fields which are readily available to students in other industrialized countries like Japan and the whole of North America. ${ }^{16}$ Such "straitjacketing tendencies"17 could negatively affect the country's economy as it has become one in need of "continuous innovation in research and

13 "Development in the Greenbelt," June 2008. City of Ottawa. 28 July 2008.

$<$ http://www.ottawa.ca/residents/public consult/beyond 2020/papers/greenbelt white paper/index en.html>.

${ }^{14}$ Janet Eve Hilowitz, Switzerland In Perspective (Westport, Connecticut: Greenwood Press, 1990) 14.

${ }^{15}$ Hilowitz, 13.

${ }^{16}$ Hilowitz, 14.

${ }^{17}$ Hilowitz, 14. 
development." ${ }^{18}$ "Switzerland is now one of the foremost countries in Western Europe using computerized automation in manufacturing." ${ }^{19}$ The more damaging effect is that, with such a pronounced contrast between "intensive modernization and tenacious traditions" ${ }^{20}$, their positive national self-image, rooted in the enduring myth of Helvetism, is deteriorating. ${ }^{21}$ With a fixed mythology and an ever-changing reality, the stress of this relationship is exerted on the feeling of national identity as younger and more reflective Swiss feel disaffection from a past that now seems all too remote.

Conversely, Ottawa, a city unfettered by centuries of tradition, has been much more eager to trade in its industrial past for that of the 'green capital' while also vying to be at the forefront of the high-tech and bio-tech industries. Selfpresentation and identity politics are serious business in Ottawa, a capital city that is "trying to be world class." ${ }^{22}$ In Urban Communication: Production, Text, Context, Caroline Andrew speaks of Ottawa as a city trying to assert itself more forcefully on the international scene by investing in marketing slogans, inventing growth strategies, and manufacturing new images. One such initiative cooked up by The Ottawa Partnership (TOP), a group created in 1999 formed of "private and public leaders who are committed to advancing the local economy"23, was to "brand' Ottawa as something more than a capital city. Their brainchild, announced publicly

\footnotetext{
18 Hilowitz, 14.

19 Hilowitz, 14.

${ }^{20}$ Hilowitz, 16.

${ }^{21}$ Hilowitz, 16.

22 Gibson, 127.

${ }^{23}$ Gibson, 132.
} 
"with great fanfare"24 was: "Ottawa: Technically Beautiful" ${ }^{25}$, an expensive flop which garnered much ridicule. With funding from the regional government and the Ontario Ministry of Economic Development and Trade, TOP hired a big American consulting firm to help them develop their "Economic Generators Initiative"26 which ultimately led to "Ottawa: Technically Beautiful."27 Entrusting such a key issue to a group capable of such an embarrassingly flagrant blunder serves to show the city's shortsightedness and immaturity in imagining how to present itself on the world stage.

For people to feel as though they belong to a period in time, to an ongoing history, they must feel a connection to their history. They must feel engagement so that, as historical influence shapes them, their contribution, in turn, helps shape it. Identity is an integral part of history. For history to remain fluid, identity must be able to suffer redefinition in synchronization with the passage of time in order to remain relevant. Both Bern and Ottawa are undergoing an identity crisis because neither accepts the role of a fluid or living history in the recognition of self. In our lives, we do not let our infancies determine the people we'll be as adults. All the steps along the way are landmarks which cumulatively determine the people we evolve to be. With discontinuous, truncated histories, it is difficult to know for certain whom we are. Rather than drawing an evident conclusion about how each city could improve and naively attempting to reverse the momentum of firmly

\footnotetext{
${ }^{24}$ Gibson, 132.

${ }^{25}$ Gibson, 132.

${ }^{26}$ Gibson, 132.

${ }^{27}$ Gibson, 132.
} 
established trends which comprise countless factors and circumstances, for the sake of the 'Ecology of Architecture', it is more important to understand the relatedness of history and identity and the influence this relationship has in the functioning of cities. From this perspective, it becomes important for an architect to acknowledge his/her responsibility in affecting history in that his/her actions will contribute to a continuation of it as well as a contemporaneous representation of a place and its people. 
Weathering: Seeing Through Rhetoric

Ottawa's ByWard Market is readily identifiable as an historic area. In broaching the subject of a design strategy in this place, the principles outlined in this dissertation stipulate that the architect must become properly familiar with the area. He/she must observe building types, function, materiality, local phenomena, and scale for the breadth of the area in question. The architect mustn't simply observe and replicate or imitate but must evaluate those elements he/she deems authentic. He/she may abstract, derive, and generate so long as his/her decisions are logically reasoned and the design innovations he/she chooses to introduce are intended to "augment reality" 28 , meaning to enhance the qualities that make a certain place recognizable.

Observing the section that was designated 'Lower Town', the original buildings that remain are easily discernable. Brick or stone are the materials common to most of these older buildings. They endure principally due to their materiality. These materials, as opposed to the materials of industrial production (steel, glass, concrete) have the capacity to incorporate into the depths of their surfaces, all sorts of deterioration "especially the kind that results from weathering as a part of aging." 29 Thus, they retain a certain 'newness' over time. In their book On Weathering: The Life of Buildings in Time, Mohsen Mostafavi and David Leatherbarrow present a convincing case for dissenting with the modernist view on

28 David Leatherbarrow and Mohsen Mostafavi, On Weathering: The Life of Buildings In Time (Cambridge, Massachusetts: Massachusetts Institute of Technology, 1993 ) 97.

29 David Leatherbarrow and Mohsen Mostafavi, "On Weathering: A New Surface Out of the Tracks of Time," Daidalos, Vol. 43 1992: 116. 
materiality as they demonstrate that weathering may not be only an operation of subtraction on a building's durability but may be a "process that can productively modify a building over time." ${ }^{30}$ Alone, a consideration for weathering does not constitute a comprehensive design strategy yet its implications in culture, history, and for the environment make it a worthy subject of study.

Mostafavi and Leatherbarrow focus on the point in time that was the transition from traditional modes of production to the Industrial Revolution. The rise of Modernism was contingent upon this transition and the accompanying wave of innovation made it difficult for anyone to swim against this current in architecture. The city of Ottawa was just one of the many North American cities in development during this time of unprecedented upheaval in human history. This particular historic moment provides the backdrop for my argument centering on the back and forth between historic stasis and modern innovation. The weathering of materials is the crux of this argument, a comparison between the work of an iconoclastic modern, Alvar Aalto, to that of a mainstream modern, Le Corbusier, shall serve to prove that one need not abandon tradition in order to achieve a transcendent architecture. The former believed in site, designing for climate, and material. The latter extolled the virtues of mass production and the machine as a model for contemporary living. Le Corbusier's 'white architecture' was a reflection of the spirit of the Industrial Age. It was fundamentally flawed as he failed to anticipate the effects of time and climate on his placeless designs. In embracing weathering,

${ }^{30}$ David Leatherbarrow and Mohsen Mostafavi, On Weathering: The Life of Buildings In Time (Cambridge, Massachusetts: Massachusetts Institute of Technology, 1993) 42. 
Aalto's ideology was much more in keeping with the modern axiom of 'perpetual newness'. ${ }^{31}$

To arrive at a proper understanding of Aalto, it is necessary to trace the source of his architectural ideology: his home country of Finland. The collective will of the Finnish people is strong. Historically, due to the poverty of the country and the remoteness of its locales, its architecture was modest, responding principally to the demands of frugality, practicality and necessity ${ }^{32}$, a philosophy not entirely dissonant with that of the International Style in the early twentieth century. Expression "was confined to the nature of materials." ${ }^{33}$ Currently, due to a period of lasting peace, stability, social order, productivity and independence, Finland is stable and prosperous. Its citizenry is enlightened and well educated. There is a cultural sophistication in their outlook on themselves and the world as the Finns begin to leave behind their image as a staid parochial society, slightly reluctant to be noticed on the world stage. There is a widespread recognition within Finland, of the importance of the arts fostering a national sensitivity to artistic endeavours and a consequent cultural dynamism. This may be attributed to two indelible Finnish characteristics: "intense individualism and determined utilitarianism"34, two seemingly discordant qualities which unite artistically and architecturally in forming a belief in, amongst other things, the superiority of a designed building in fulfilling the

${ }^{31}$ David Leatherbarrow and Mohsen Mostafavi, On Weathering: The Life of Buildings In Time (Cambridge, Massachusetts: Massachusetts Institute of Technology, 1993) 86.

${ }^{32}$ Michael Dobbins, "The Achievement of Finnish Architecture: Social Responsibility and Architectural Integrity," Perspecta, Vol. 8 1963: 3.

${ }^{33}$ Dobbins 3.

34 Dobbins 3. 
twin demands for utility and self expression. In its adherence to certain criteria such as appropriateness, thoroughness, and social responsibility, Finnish architecture has distinguished itself internationally as unfalteringly principled. "Less tangible but nevertheless deeply meaningful, is the reflection of the Finnish land and the character of its people in each building." ${ }^{35}$ Given these national characteristics, it becomes transparently clear why Aalto couldn't blindly subscribe to the doctrines of modernism no matter how 'au courant', even at the risk of appearing gauche or out of step with the current trends. The so-called "hero of regionalist architecture"36 couldn't permit himself to ignore climate, site, and "above all, material."37

In the 1920s and 1930s, Aalto put Finland on the international map. A 1928 commission, the Turun Sanomat newspaper building in Turku, Finland, is described as his "purest International Style work"38 exhibiting all the familiar subjects: ribbon windows, white stucco walls, steel-framed windows, freestanding concrete columns, and the free plan. ${ }^{39}$ Despite its supposed modern purity, Aalto, taking into consideration the imperatives of the Finnish climate, incorporated wall vents and insulated spandrels, blatant contraventions of the International Style code. The Paimio Sanitorium for tuberculosis, completed in 1932, is also modernist in appearance but more humanist in character. Humanist here, referring to the deference paid to the occupants and their requirements above the purely esthetic

35 Dobbins 4.

${ }^{36}$ Edward R. Ford, The Details of Modern Architecture - Volume 2: 1928 to 1988

(Cambridge, Massachusetts: Massachusetts Institute of Technology, 1996) 119.

37 Ford 119.

${ }^{38}$ Ford 119.

39 Ford 119. 
concerns of a devoted adherent to a school of thought. Each of the hospital's four wings is structurally dissimilar to the others and the structure remains largely hidden. Aalto determined the orientation of each wing in relation to sunlight and ventilation and bay spacing according to the programmatic requirements of the rooms. ${ }^{40}$ The deep penetration of natural light was facilitated by high windows and surfaces painted to reflect that necessary light in various ways. At that time, fresh air and natural light were thought to be essential therapeutic elements, along with the limited medical treatments of the day and Aalto made allowance for these in his architectural plan. Aalto's motivations were already reaching beyond the modernist agenda toward more fundamental concerns in his architectural vision such as the properties of materials, their behaviour in light, and the effect of both of these on the occupants. It's important to note that, to him, "the industrial, the natural and the vernacular were not mutually exclusive languages." ${ }^{41}$ Aalto "saw himself as simply humanizing the impact of industrialization on modern life." ${ }^{\prime 2}$ He was anticipating the pitfalls of an environment composed of mass-produced, standardized parts by acknowledging the necessity for integration of the human element into his work. It can safely be said that his Finnish heritage and character allowed him to view modernism more critically than some of its more orthodox adherents.

\footnotetext{
${ }^{40}$ Ford 123.

${ }^{41}$ Ford 119.

42 Ford 127.
} 
According to the principles of the modern movement, traditional earthen materials that weather, such as brick and stone, materials that reveal the effects of time and climate, are synonymous with deterioration. The materials of industrial production such as stucco, steel, concrete, glass, materials meant to resist the effects of time and climate and retain their newness always, were synonymous with virtuousness and liberation from the traditional and antiquated pre-industrial systems. In completely eschewing tradition in favour of the systems of mass production, architects and builders found themselves in unfamiliar territory as these new materials required new methods of assembly and little could be anticipated with regard to their long term sustainability. Specialized building techniques required more instruction and therefore a greater dependence on the architect. At one time, the relationship between the architect and builder weighed more heavily upon the builder's knowledge of his craft but in the absence of a precedent, neither the architect nor the builder could predict how these new buildings would behave. Intended as a universally applicable model, the unadorned, flat, white modern box proved to be a disappointment. Theoretical perfection doesn't hold up well in the face of reality. An ideology wavers in the harsh light of the physical reality: the actual emplacement in which a building must physically exist. Interestingly, by the mid-seventeenth century in Georgian London, "bricklaying had become such a fine art that brickwork could be made to look perfectly uniform." ${ }^{\text {"43 }}$ The brick units had become so precisely made that a wall constructed of brick closely approximated

${ }^{43}$ David Leatherbarrow and Mohsen Mostafavi, "On Weathering: A New Surface Out of the Tracks of Time," Daidalos, Vol. 43 1992: 119. 
the flat appearance of one made of stucco or stone. ${ }^{44}$ These walls, however, were outfitted with 'weatherings' ("elements that regulate the downward flow of water"45) or 'ornaments', which were deplored by the modern movement. Without weatherings, durable materials, and a consideration for context, buildings of the modern era were much more vulnerable to the elements and thus, much less durable. However, the vehemence of those supporting the modern ethos principally Le Corbusier, the foremost pioneer and propagator of modernism's distancing and self-reflective techniques, seemed to make abstraction of issues such as weathering and durability in modern structures. The dismissal of these issues was not without consequences. Hypocritically, Le Corbusier replaced photographs of Villa Savoye (completed 1929) for his drawings of the building in his Oeuvre complète Nolume 1 - 1910:1929) "because at many points its deteriorated condition had the potential to undermine the idealist, formalist history that had been constructed for it." ${ }^{46}$ Villa Savoye, the quintessential embodiment of Le Corbusier's five principles and the internationally recognized modern building, had begun to decay "almost before the house was completed." 47 From the years 1930 to 1937, the owner, Émilie Savoye, corresponded with Le Corbusier and she documented the innumerable leaks. ${ }^{48}$ They weren't merely leaks. Mrs. Savoye claimed that it

44 David Leatherbarrow and Mohsen Mostafavi, "On Weathering: A New Surface Out of the Tracks of Time," Daidalos, Vol. 43 1992: 119.

${ }^{45}$ David Leatherbarrow and Mohsen Mostafavi, "On Weathering: A New Surface Out of the Tracks of Time," Daidalos, Vol. 43 1992: 119.

${ }^{46}$ Kevin D. Murphy, "The Villa Savoye and the Modernist Historic Monument," The Journal of the Society of Architectural Historians, Vol. 61, No. 1 Mar. 2002: 70.

${ }^{47}$ Murphy 73.

${ }^{48}$ Murphy 73. 
was raining in different parts of the house. By the late 1950s, the house had fallen into almost ruinous disrepair.

A building that was absent from Le Corbusier's Oeuvre complète was the Villa Schwob (1916-17). One of his earliest buildings, it was composed of brick masonry. Its exclusion from the book of his collected works serves to indicate that prosaic brick, "a material with colour, texture, variety and surface imperfections" 49 had no place amongst the representatives of the "age of truth" 50 in modern architecture, those being buildings such as the white Villa Savoye.

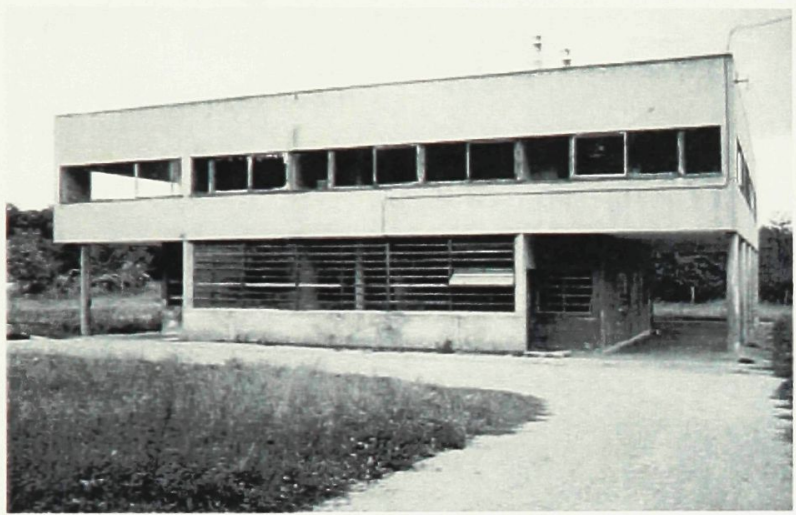

Fig. 5 - Derelict Villa Savoye, Poissy-sur-Seine, France (1928-31), Le Corbusier.

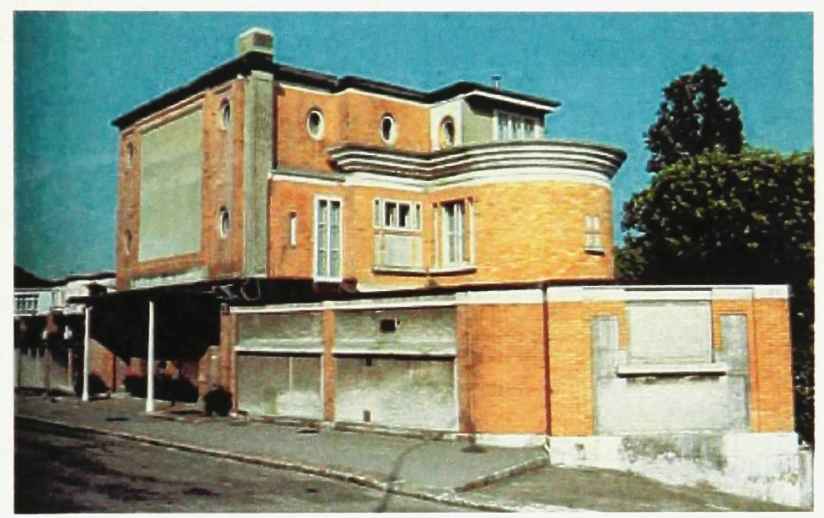

Fig. 6 - Villa Schwob, La Chaux-de-Fonds, Switzerland (1916), Le Corbusier.

Contrary to what he had intended, Le Corbusier's white modern boxes did come to represent truth as they quickly began to show markings and defects of construction and, by extension, the defects of the International Style. Conversely, brick underlines truth as a function of aging. The durability of brick, in revealing the passage of time much more slowly and gracefully, is a much 'truer' material. The use of such a material by an architect presupposes his understanding and

49 David Leatherbarrow and Mohsen Mostafavi, "On Weathering: A New Surface Out of the Tracks of Time," Daidalos, Vol. 43 1992: 116.

50 David Leatherbarrow and Mohsen Mostafavi, "On Weathering: A New Surface Out of the Tracks of Time," Daidalos, Vol. 43 1992: 116. 
acceptance of weathering which "brings the project closer to a condition of actuality based on its potential transformations through time" 51 which, in turn "complements the ideality of the project, making it both independent of the passage of time and caught up with it." ${ }^{\text {25 }}$ As it is the purpose of a building envelope to protect its occupants from the weather, the 'deterioration' of brick as an actual truth is incontrovertible when compared to the fading truth of the White. Not surprisingly, Villa Schwob has aged well compared to the work that appeared in Le Corbusier's Oeuvre complete. Viewed in this context, the concern demonstrated by Aalto seems far more professional and forward thinking than the foolish 'modernity' of rejecting convention at any price.

In 1947, Aalto received his second commission in the U.S. at the Massachusetts Institute of Technology. Baker House, a six-story student dormitory, was the iconoclastic modern's first foray into brick masonry as an exposed exterior cladding material. ${ }^{53}$ He paid homage to the local Georgian vernacular by using a "rough, waterstruck New England brick." ${ }^{\text {4 }}$ The building was remarkably resilient and underwent its first major renovation fifty years after it was completed in 1999. Aalto's design for the dormitory had originally included an aluminum trellis system meant to support greenery on the south façade but it was never constructed. Despite this omission, the masonry cladding showed no

${ }^{51}$ David Leatherbarrow and Mohsen Mostafavi, On Weathering: The Life of Buildings In Time (Cambridge, Massachusetts: Massachusetts Institute of Technology, 1993) 112.

52 David Leatherbarrow and Mohsen Mostafavi, On Weathering: The Life of Buildings In Time (Cambridge, Massachusetts: Massachusetts Institute of Technology, 1993) 112.

${ }^{53}$ David N. Fixler, "The Renovation of Baker House at MIT: Modernism, Materiality, and the Factor of Intent in Preservation," APT Bulletin, Vol. 32, No. 2/3 2001: 4.

${ }^{54}$ Fixler 4. 
significant deterioration and required no restoration. Ironically, the portion of the façade that necessarily had to undergo reconstruction was the stucco cladding system for the north stair. The architect had specified an unglazed terracotta tile on light gauge steel framing for this façade but the contractors disapproved of this part of the design because of concerns that they had about the uncertainty of the behaviour of such a system and unreliability in the method of its construction. The builders opted instead for the stucco, a material they judged to be more reliable. Unfortunately, the inclusion of the tile as part of the renovation was vetoed again due to the system's unpredictability and for budgetary reasons. Aside from this, other than the stair, the building required no other major renovations. Cosmetic refinishing of all interior woodwork was carried out. A balustrade from Aalto's original design was included and adapted to suit current safety standards. Initiatives regarding integration of modern technology, fire-protection systems, new mechanical units for supplemental heat and air conditioning, and better lighting were also addressed and executed in a most sensitive manner..$^{55}$ Aalto's first attempt at brick masonry construction was in a new country where Aalto had to adapt to an unfamiliar climate and construction industry. However, in spite of the fact that Baker House was a novice effort in terms of its materiality, it has stood the test of time. From an overall architectural standpoint but specifically from the position of weathering, it has achieved what many buildings of the modern period could not. Aalto expressed his belief plainly: "It is not what a building looks like on

\footnotetext{
55 Fixler 8-9.
} 
opening day - but what it is like thirty years later that counts." ${ }^{56}$ At fifty years of age, Baker House stands relatively undeteriorated revealing little of its age.

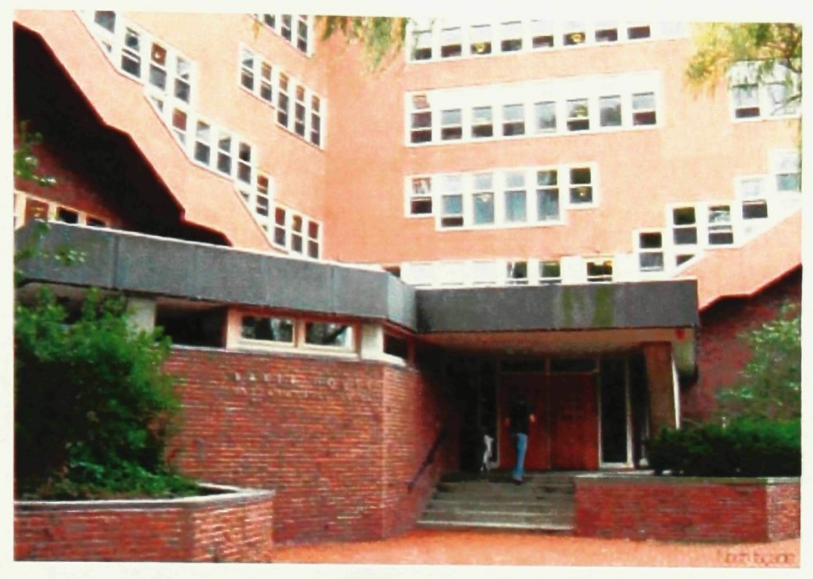

Fig. 7 - Baker House, MIT, Cambridge (1947-8), Alvar Aalto. September 2005, after restoration. North façade.

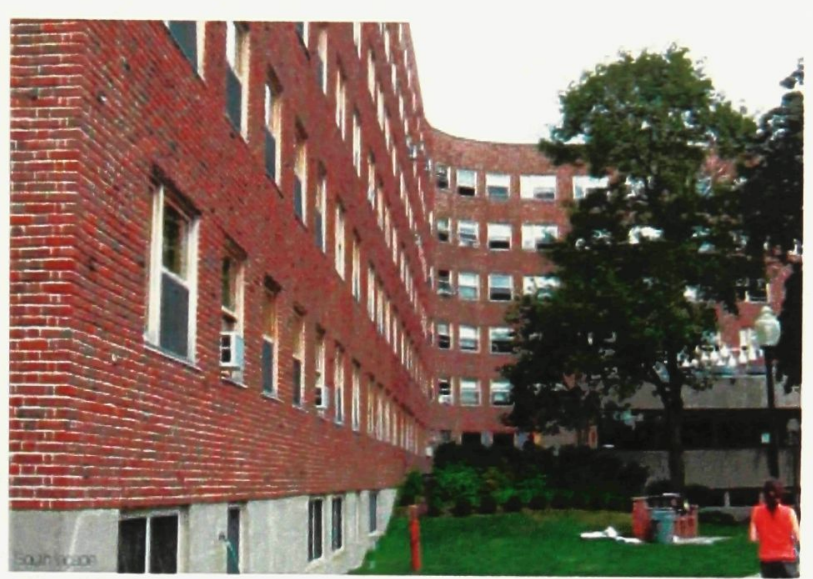

Fig. 8 - Baker House, South façade.

Baker House was only the first among many brick masonry buildings to be realized by Aalto later in his career. His recognition of the importance of brick as a weathering material culminated in the construction of a full-scale experimental house that was his 'Summer House' in Muuratsalo, Finland in 1953. The walls of the courtyard combine "over fifty areas wherein different types and sizes of bricks and tiles are arranged in various patterns of jointing." ${ }^{57}$ This 'tapestry' was intended as a "test case for studying the characteristics of different forms of brickwork in a given location over time." ${ }^{58}$ As postulated by Leatherbarrow in On Weathering: A New Surface Out of the Tracks of Time, Aalto understood brick's ability to renew its finish over time. Thus, its usage suggests intentionality on Aalto's part in

${ }^{56}$ Fixler 10.

${ }^{57}$ David Leatherbarrow and Mohsen Mostafavi, "On Weathering: A New Surface Out of the Tracks of Time," Daidalos, Vol. 43 1992: 123.

${ }^{58}$ David Leatherbarrow and Mohsen Mostafavi, "On Weathering: A New Surface Out of the Tracks of Time," Daidalos, Vol. 43 1992: 123. 
anticipating the factor of weathering in the life of his buildings, which, as previously mentioned, "brings a project closer to a condition of actuality based on its potential transformations through time." ${ }^{59}$ Authenticity in Aalto's work subsumed other considerations. For Aalto, it involved "a dynamic compromise between the use of materials, both modern and traditional, in the configuration of nontraditional form and space, and his understanding of the fundamental centrality of the human experience in architecture, grounded in the coloration of his native Finland." ${ }^{\prime 60}$ From his particular point of view, Aalto objectively evaluated the doctrines of modernism. He appropriated some of the ideology of the movement and adapted it to suit what he deemed to be correct and, in so doing, contributed a valid and important counterpoint, one that served to augment reality because it was productive and long-lived. ${ }^{61}$

Aalto's architecture, although less influential than that of some of the more glittering exemplars of the school, modestly resonates modern themes in his treatment of light, use of structure, and in the spatiality of his buildings but it is in his instinctive adherence to his own individual and particular principles that he achieved an architecture that isn't entrenched in a period of time but still living, that is weathered but still new.

59 David Leatherbarrow and Mohsen Mostafavi, On Weathering: The Life of Buildings In Time (Cambridge, Massachusetts: Massachusetts Institute of Technology, 1993) 112.

${ }^{60}$ Fixler 3.

${ }^{61}$ David Leatherbarrow and Mohsen Mostafavi, On Weathering: The Life of Buildings In Time (Cambridge, Massachusetts: Massachusetts Institute of Technology, 1993) 97. 
The Abilene Paradox states that: "People in groups tend to agree on courses of action, which, as individuals, they know to be stupid."62 Groupthink is a dangerous scenario that we partake in to our detriment. The modern movement gained momentum based on unfounded proclamations about life in an industrial world and its proponents believed in it, despite it not yielding the liberation it prophesied. Similarly, today, neighbourhoods erected overnight, accretions of endlessly sprawling suburbs, composed of ticky-tacky boxes are what developers insist purchasers want. This, in spite of the fact that subsidized and low-rent housing is actually what is most needed by the majority of purchasers. Affordable housing near amenities and within reasonable distances for shopping and doing business is the actual requirement. Are developers giving people what they really need? Are commutes, expensive gas, and identical McMansions the best response to the needs of housing consumers? Indisputably, the sole purpose of these developments is a rapid turn-around for easy profit. Each home is uniform, standardized, and built to meet a minimum standard for code and quality. A brick masonry façade is common to many of these homes, a recognized symbol of quality, but they are merely façades as the rest of the envelope is usually composed of cheaper, environmentally harmful materials such as vinyl siding. Like the white, unadorned boxes of modernism, these homes are ignorant of site and weather and therefore cannot endure. It becomes important in such scenarios to heed

62 John Peers and Gordon Bennett, 1,001 Logical Laws, Accurate Axioms, Profound Principles, Trusty Truisms, Homey Homilies, Colorful Corollaries, Quotable Quotes and Rambunctious Ruminations for All Walks of Life (New York, New York: Fawcett Gold Medal, 1979) 13. 
dissenters, such as Aalto, who question the status quo. It behooves architects, builders and developers alike to pay some mind to presenting the housing market with some exciting, innovative, affordable, durable, and attractive housing within the economic grasp of a majority of buyers. It is also imperative that thought be given to the future of the developments in an age of increasing environmental consciousness. The old proverb "haste makes waste" has never been more applicable. 
Perpetuation Over Preservation: Architecture as Oral History

One morning in Bern, I sat on a park bench and reflected on Albert Einstein. In that particular city, in that particular park, on that particular bench it seemed not only natural but appropriate to let my mind wander to thoughts of its most notable resident. I was living in the city in which he had worked as a patent clerk and where he had conceived his theory of relativity. He was the same age I was as I sat there that day, and I couldn't help but wish for a comparable moment of insight when it comes to my chosen profession. I was not so much concerned with the significance of his theory as much as I was with the series of events in his life which had led to his epiphany. Had he walked to a café that morning and sat on this same bench eating an overpriced croissant as I had? It's conceivable that my steps and his could have coincided as the urban fabric of Bern has changed very little physically. My concerns most definitely cannot be confirmed by consulting a textbook on physics and are perhaps of little importance to a historian tracing the broad strokes of Einstein's life but they were extremely important to me as I sat there that morning in that place, during that time in my life. I didn't want to talk to a theorist. I wished for a Swiss contemporary of Einstein's to join me on my bench, to answer my questions with first hand accounts of the man's words and experiences undiluted, specific, and personal.

We speculate when we are unable to know for certain. Logically, it would always be preferable to consult the source for a true account. This thought transposed itself onto my underlying concern as I sat there that day. Namely, older 
buildings that have endured the onslaughts of time and weather are the genuine article, direct conduits to the lives and traditions of past generations of architects, craftsmen, builders and planners. Considered from this perspective, architecture functions as a visual, tactile history rather than a written account. It's like talking to the man himself and not reading about him in a book. The actual building is, by virtue of its undeniability and its durability, a more immediate and important historical document, one that bridges time and operates in a different dimension from the intellectual or theoretical accounts of the past. I came away from the moment with some elusive ideas and some questions about ways of knowing and understanding the built environment and about the need for insight into something as ubiquitous as how buildings age if $\mathrm{I}$, as an architect am to maximize the experience of creating something that will testify to others.

The academic record of history reports broadly and is subject to manipulation over time as it passes through the hands of many and succumbs to bias, interpretation and reinterpretation, and political pressure. American writer Alex Haley famously observed: "History is written by the winners." ${ }^{63}$ Humans are eager for the next new thing and easily led to believe that change equals progress. This accounts for the eagerness with which many eradicate vestiges of the past. Much of this alteration is justified I suppose, but some of it needs re-thinking. For example, the slow erasure of Ottawa's original fabric is a commonplace occurrence, one which erodes this unique city's identity. Essentially, each time a

63 “Alex Haley Quotes,” 2007. UBR Inc. 5 August 2008.

$<$ http://www.people.ubr.com/authors/by-first-name/a/alex-haley/alex-haley-quotes.aspx>. 
storied old building falls, it is like the burning of a papyrus scroll containing priceless knowledge that can never be retrieved. A newspaper article, textbook photo, or an academic research thesis cannot recreate the texture and the value and essence of the genuine article. Keeping up a dialogue with the past is essential to enriching the present and, subsequently, the future meaning of this and other cities.

The special stewardship required to protect and preserve cities like Ottawa is entrusted to organizations such as 'The Heritage Canada Foundation' or other such groups whose mandates are the preservation and conservation of buildings and areas deemed 'historic'. Once a building is canonized, set apart, it is a moment frozen in time and no longer "a living, changing artifact of human use." 44 In 'framing' a certain building in this way, we trust a person's interpretation of what makes a building historic, what makes it worthy of being treated like an object in a museum. This is an academic method of classifying. Paying admission and receiving a guided tour of a building is like reading a textbook about a certain subject and never experiencing it firsthand. The building becomes a victim of interpretation and "history, and this, in a sense, imprisons the building." ${ }^{65}$ This way of treating old things in general has shaped the attitude that 'old means precious' and any physical manipulation of an object, once it has been deemed 'historic', is sacrilegious.

${ }^{64}$ Mark Alan Hewitt, "Architecture for a Contingent Environment," Journal of Architectural Education, Vol. 47, No. 4 1994: 198.

${ }^{65}$ Hewitt, 198. 
Inscribed on an Ontario Heritage Foundation plaque inside St. Brigid's Church are the words: "Heritage Conservation Easement Site - The heritage character and integrity of this property are protected by a legal agreement between the owner and the Ontario Heritage Foundation". The current owner who has taken care of the church since it was decommissioned, has been battling with preservationists. He's trying to lend the building a new use since it can no longer be used as a place of worship. He cannot take down the Crucifix which is simply tacked to a column and he cannot move a single pew. He must pay a five thousand dollar a month energy bill with very little to defray the cost. He hopes the church will be absorbed into the Rideau Canal's designation by UNESCO as a 'World Heritage Site'. His case is based on the argument that the church's original parishioners, Irish immigrants, were instrumental in the building of the Rideau Canal. Such recognition would ensure the building's protection. Otherwise, Patrick will most likely have to sell off pieces of the church including its one hundred and twenty year old pipe organ to salvage some of the cost of his investment. The most likely scenario is that the church will come down and the site will fall prey to developers. If this occurs, another unique artifact of the past will be erased. Ironically, preservation equates death whereas a redefinition in the building's use would equate to its salvation.

Why couldn't a traditional building be given a modern purpose? Isn't repurposing preferable to destroying and starting from scratch? It seems natural in other parts of the world to want to preserve the past. Why not in Canada? A 
paradigm shift must occur in which our attitudes switch from 'preservation' to 'perpetuation'.

In an attempt to support the point of view of preservationists, consider how ancient Romans dealt with their aging buildings. Roman citizens were not only encouraged to make efficient use of their old buildings it was considered their civic duty. 'Spoliation' as it's described in Spolia in Roman Cities of the Late Empire: Legislative Rationales and Architectural Reuse by Joseph Alchermes, is defined "both as the integral adaptation of buildings and as the reuse of construction materials salvaged from structures for erection elsewhere". ${ }^{66}$ Rome had begun preserving and reusing buildings and their constituent materials in the fourth century. Factors affecting such legislation were "appreciation of the city's past, pride in the present state of its monuments, and concern for the local economy." ${ }^{67}$ Pragmatic concerns were balanced with social considerations so that, in maintaining an old monument's structure, lawgivers were also promoting civic cohesiveness by maintaining the monuments of local traditions. These buildings weren't preserved to be kept as precious artifacts as is the case here in Ottawa. They were judged worthy of preservation because they were the repositories of Roman traditions. ${ }^{68}$ They were worthy of being sustained because they had earned their place in the city and maintained a sense of purpose. If the need for a new civic building were too great, then and only then would a new building be built using

\footnotetext{
${ }^{66}$ Joseph Alchermes, "Spolia in Roman Cities of the Late Empire: Legislative Rationales and Architectural Reuse,” Dumbarton Oaks Papers, Vol. 48 1994: 167.

${ }^{67}$ Alchermes, 172.

68 Alchermes, 172.
} 
materials from ruins so precarious that they endangered public safety. Ruins were always 'dismantled' to be reused and not 'demolished' to be discarded. In 364, concern for urban decorum moved legislators to allow patrons to renovate dilapidated public monuments whose ruinous state "marred the cityscape" ${ }^{69}$ In fact they graciously encouraged such initiatives primarily "to limit the useless new construction that sapped the resources of cities, and caused administrators to "fail to repair old and illustrious buildings" visibly affected by time and neglect." ${ }^{70}$ In ancient Rome, the conservation of the tangible components of urban monuments was a task equal to that of preserving civic pride, "a much less durable, nonrenewable resource". ${ }^{71}$ The same cannot be said of contemporary conventions governing building construction, maintenance, and disposal.

Buildings are typically felled without regard for reusability. The LEED initiative, as farsighted as it is, is simply a guide and not hard-and-fast legislation. There is no legal principle in place to ensure that all potentially reusable parts of a building are salvaged. In Ancient Rome, it was law. Today, it's a choice left to the proprietor's discretion. Likewise, as a by-product of ignoring the economic benefits of reuse in demolishing and building anew, Ottawa's original fabric is being erased and its unique identity is slowly being eroded. What happens to city residents' sense of belonging when their city loses its cachet? What, if not its architecture,

\footnotetext{
${ }^{69}$ Alchermes, 173.

${ }^{70}$ Alchermes, 173.

${ }^{71}$ Alchermes, 178.
} 
lends a city its identity? How can ancient Roman civilization have had a more progressive outlook than our own in the twenty-first century?

A living example of Rome's enduring faithfulness to their laws on reuse is the Theatre of Marcellus. "Begun by Julius Caesar in 44 B.C., and completed by Augustus between 13 an 11 B.C." ${ }^{72}$, this theatre still exists in modern Rome although visually and programmatically dissimilar from its original incarnation.

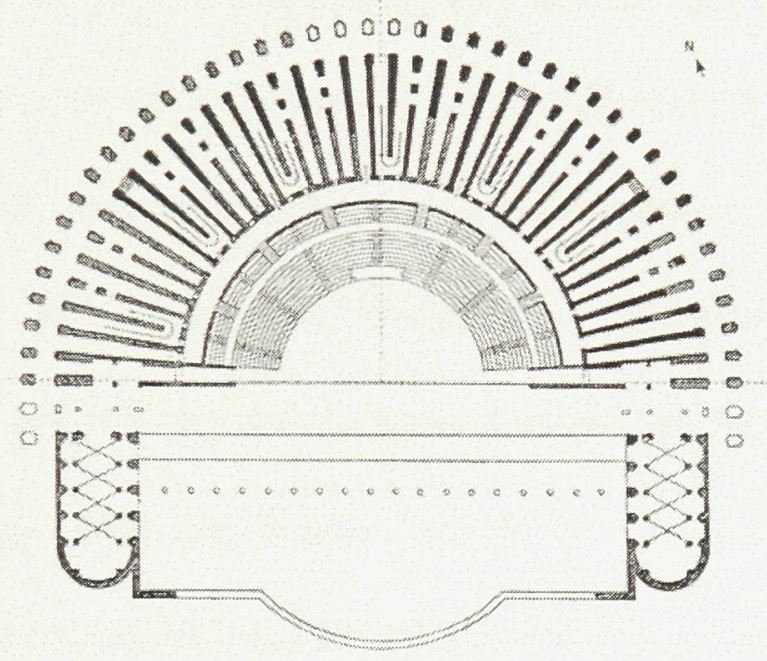

Fig. 9 - Theatre of Marcellus, Rome (13-11 BC), Plan.

Chronologically, the different notable periods in the building's life are as follows: in 64 A.D., the building was suspected of having been damaged by fire. By the time of Emperor Trajan, the theater's "outer radial substructures were used as tabernae" ${ }^{\prime 33}$, which can be either mercantile spaces or possibly also living quarters. In 365 A.D., near the time the legislation regarding reuse was introduced, travertine blocks for the theatre were used in the reconstruction of another building however,

${ }^{72}$ Frank Sear, Roman Theatres: An Architectural Study (New York, New York: Oxford University Press Inc., 2006) 61.

${ }^{73}$ Sear, 62. 
later in the fourth century, there's evidence that suggests the building was still in use as a theatre. ${ }^{74}$ "In the Middle Ages the building began to collapse and fill with sand and mud from Tiber floods. Numerous accretions gave it the appearance of a mountain, a name by which it was commonly known during this period.." ${ }^{75}$ In 1532 , in the care of the Savelli family, the theatre was converted into a palace. Until the $20^{\text {th }}$ century, the building had changed hands but had largely remained unchanged and there had even been plans to liberate the theatre from its residential additions and resurrect its original function however, as part of something called the 'Via del Mare Project', its accretions were removed and the building was reduced simply to the Palazzo Savelli. As it appears today, the residential portion from the Renaissance and the original stone structure of the theatre are easy to differentiate visually but structurally, they are indistinguishable. They are fused together so strongly that a separation would likely be implausible if not impossible. The building is two thousand twenty years old and is still fulfilling a useful function. This building is tangible history, a true survivor. Its story is legible in its many layers. Its endurance is a testament to its materiality. A similar phenomenon, albeit far less pronounced, is observable

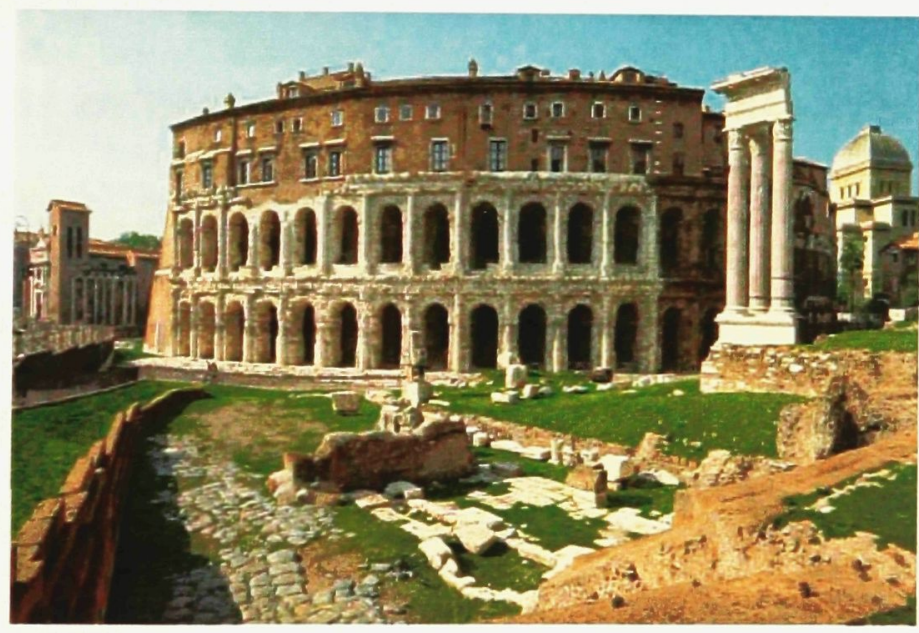

Fig. 10 - Theatre of Marcellus, Rome, present-day.

\footnotetext{
${ }^{74}$ Sear, 63.

75 Sear, 63.
} 
in the case of St. Brigid's Church.

The question of 'how to treat a building like the Theatre of Marcellus', a true example of sustainability, is one fraught with ethical implications. In Architecture for a Contingent Environment by Mark Alan Hewitt, the author goes into detail about how to responsibly affect so-called 'historic' buildings. It's Hewitt's contention that academic institutions, specifically North American ones, of the twentieth century have approached the challenge of intervention in a shortsighted way. He urges that a work of architecture be seen not as a thing unto itself requiring care like a museum artifact, but as a precarious, contingent piece "in a larger preexistent order". ${ }^{76}$ If, from the outset, the architect perceives a building as belonging to its surroundings and imagines that the two are inextricably linked, part of a "morphologically continuous, temporally fluid system undergoing a larger metamorphosis" ${ }^{77}$, how might this realization affect the problem of intervention? If an architect anticipates that a building and its site, together forming a sort of subecology, are a dynamically evolving system affected by human actions, climate and time, he/she is beginning to envision a solution from a more realistic standpoint. ${ }^{78}$ Aalto's ability to anticipate the factor of weathering in the life of his buildings is an example of a strategy that communicates this point. It must be said that, whatever the degree of intervention, there is no such thing as a neutral approach in addressing the problem of reuse. Some ideological value will be

${ }^{76}$ Mark Alan Hewitt, "Architecture for a Contingent Environment," Journal of Architectural Education, Vol. 47, No. 4 1994: 200.

77 Hewitt, 200.

78 Hewitt, 199. 
imparted and, thus, it is important to establish boundaries as to the comprehensiveness of the interpretive frame on the $\operatorname{artifact~}^{79}$ so that the design response is appropriately tempered.

${ }^{79}$ Hewitt, 199. 
Inherently, European designers in general have had to deal with this dilemma much more than architects in North America, consequently, Europeans are "far more knowledgeable about historic buildings (both aesthetically and technically) and hence less self-conscious about the prospect of operating on a venerated artifact". ${ }^{80}$ Hewitt explains that architectural education has traditionally propounded two theories for conservation in architecture: the stylistic-unit theory or conjunctive theory and the disjunctive theory. ${ }^{81}$ In the former, the intervention's purpose is to restore the building's appearance to its originally intended, complete form. In the latter, the contrast between the newly designed addition and the existing structure

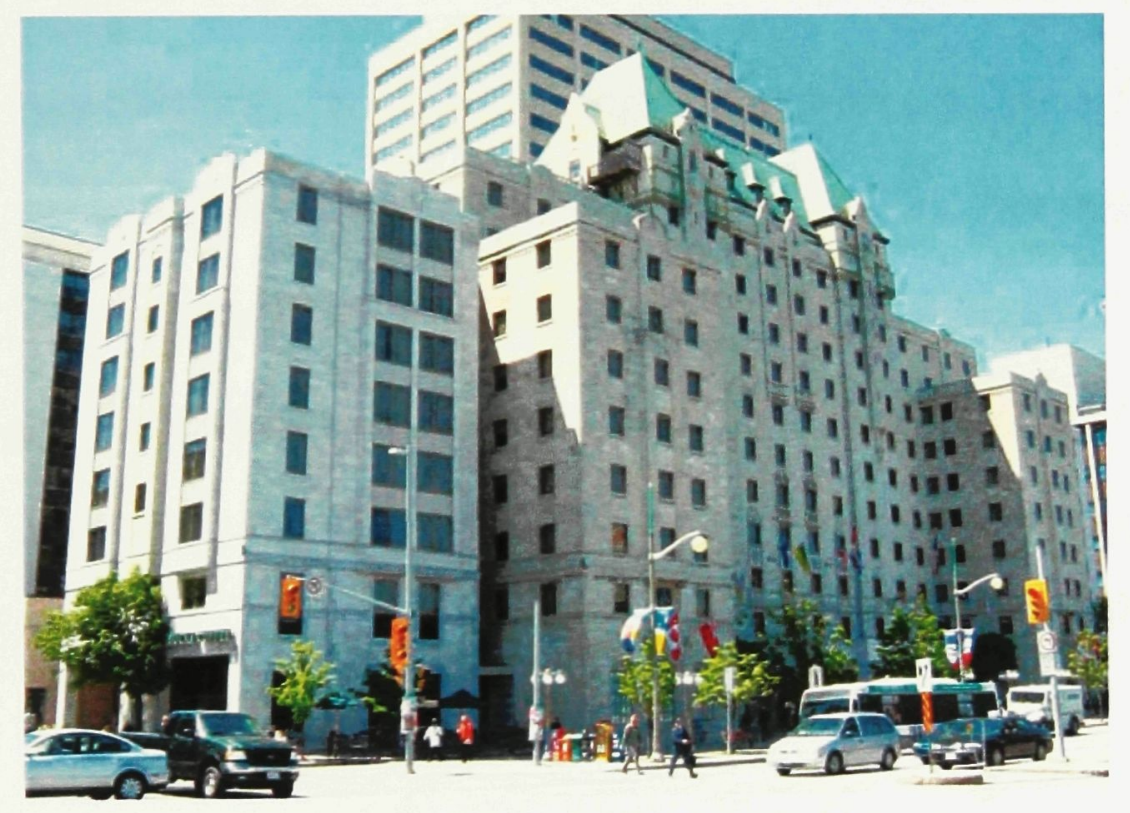

Fig. 11 - Lord Elgin Hotel, Ottawa, Ontario (1941). South block addition completed 2002. Example of conjunctive theory. is explicitly clear. The

criticism common to both views is that they each result in an artifact distinctly apart from its surround. Hewitt posits the notion of 'architectural intervention as

\footnotetext{
80 Hewitt, 198.

81 Hewitt, 199.
} 


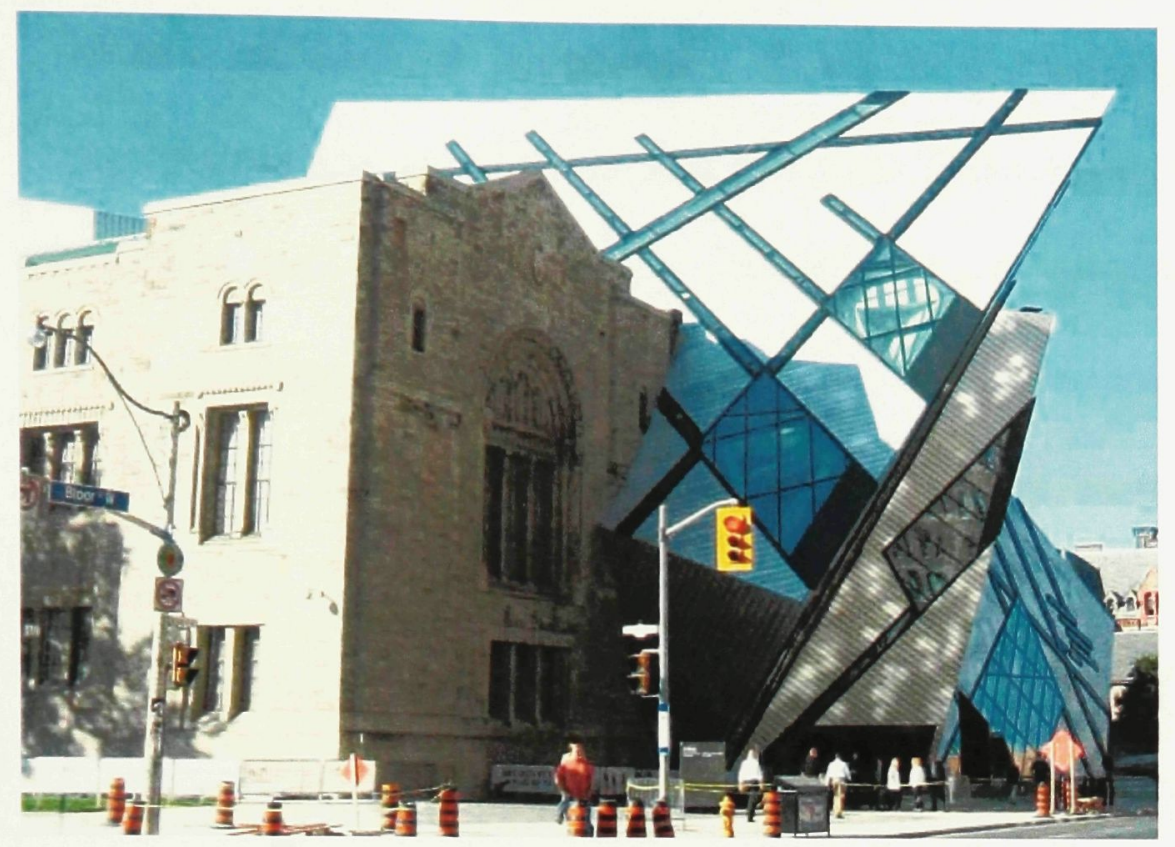

Fig. 12 - Royal Ontario Museum, Toronto, Ontario (1914). Third expansion by architect Daniel Libeskind and Bregman + Hamann Architects, projected to be complete by 2010. Example of disjunctive theory.

intermediary", "a kind of in-between fabric to be knitted into the preexisting environmental order" ${ }^{82}$ As mentioned above, this method asks that architects change their way of perceiving a work of architecture to include its context so that our jobs inflate to include input from different but related fields such as cartography, geography, archeology, sociology, conservancy, and history together.

Practically, this philosophy translates into different site analysis exercises. As a way of discovering the 'in-between' realm for historic sites, students are encouraged to thoroughly research the history of a site to find drawings containing different types of data such as figure-ground drawings, contour maps, landscape drawings, archeological plans, variable representations of urban grids showing building development at different historical times, and cross-referencing these and layering them in ways to discover trends or anomalies which may help germinate a 
relevant architectural hypothesis. There is a modeling approach called the 'constructed site' in which "factors of human intervention, landscape, climate, and natural forces contribute to a model of built morphology rather than the conceptualized, mathematical matrix or carte blanche site assumed by so much modernist pedagogy". ${ }^{83}$ Another method consists of the macroscopic analysis of a city's fabric. Colliding city grids, building remnants, and damaged and disused infrastructures provide opportunities for unveiling "buried meanings"84. Critically thoughtful insertions at such nodes make new fabric that conflates the past and the present, a much more valuable strategy than placating history with a formally obedient, contextually conforming design. A challenge present both in North America and Europe is in introducing this so-called intermediary into highly regulated, dense, historic districts of row houses and terraces "where continuity with existing fabric is a paramount concern". ${ }^{85}$ In areas like these that possess a thoroughly established geometry, scale, and material palette, such constraints tend to stifle creativity. However, if architects and students of architecture approach the problem as a challenge, they may find sufficient flexibility within the limited frame to uncover the potential for expression.

It isn't clear in Hewitt's use of an 'intermediary' how this 'in-between' is to be manifest. He had expressed that there's no such thing as a neutral approach. If the strategy of the intermediary isn't conjunctive or disjunctive, then what is the

\footnotetext{
83 Hewitt, 201.

84 Hewitt, 201.

85 Hewitt, 203.
} 
degree of intervention between the old and the new? The exercises listed above require that a site be thoroughly imbued with history; its history read chronologically in its strata. If there is no physical evidence of history on a site, such exercises as the palimpsest drawing and the intersection of grids lose meaning in abstraction. The conditions at the site must be right for such analyses. Not all sites can be so historically potent. The intervention must necessarily assert itself in a way when the building does metamorphose and change use because, if it is going to continue to be alive and continue to be of use, it necessarily has to suffer some modification as part of the birthing of a new use. If an existing, historic building falls out of use and a new use is proposed and implemented, this new use implies a difference in the way humans affect it. The relentless assault of weather and climate is ever-present and must also enter into consideration. The building necessarily continues to evolve, to live. If this building is still in shape after a second use and undergoes another transformation, evidence of the first two uses will necessarily remain. The building cannot revert to a previous form. If the first use were as a church, like St. Brigid's, and the second use were to be radically different as I'm proposing, even if the building's third incarnation were to be as a church again, it isn't reverting to the church that it was, it's becoming a church again with elements of both previous incarnations.

Hewitt cites the work of Carlo Scarpa, specifically the Castelvecchio Museum, as an example of architecture that is cognizant of the broader implications of contemporary interventions in historic buildings. Scarpa's work, 
however, cannot be referred to as 'intermediary'. The intervention at Castelvecchio acts much less as a mediator than it does as an unmistakably new and contrasting organism, which successfully breathes new life into an archaic relic. In Carlo Scarpa Architect: Intervening With History, his work is described as creating "a conspicuous dialectic, at times a confrontation, between old and new" ${ }^{86}$ The author describes Scarpa as insistent "on displaying the seams between the fabric and the intervention, on layering an asymmetrical form of his own behind an existing order, and on forcing fiercely new dimensions or materials against the texture of the old - like the great black steel girder that runs along the ceiling in the Museo di Castelvecchio". ${ }^{87}$ Scarpa, like Aalto, foresaw a life for his buildings that would outlast his own. In his own words, Scarpa describes the campanile on the Venetian island of Torcello: "See how a building inevitably establishes new identities over time... Once acknowledged this basic principle makes it fundamental for the architect to leave conspicuous and characteristic evidence of his own within the historic fabric, trusting time to fuse it into a comfortable whole". ${ }^{88}$ It wouldn't be just to label the Castelvecchio restoration as a disjunctive method of preservation simply because of a contrast between old and new. In trusting time, the ability for materials to patinate, and for establishing a dialogue with the past while ensuring continuity, Scarpa's architecture transcends the modernist ethos, rooted in his provenance, distinct in every way.

${ }^{86}$ Nicholas Olsberg, et al., Carlo Scarpa Architect: Intervening With History (New York, New York: The Monacelli Press, Inc., 1999) 14.

${ }^{87}$ Olsberg, et al., 14.

${ }^{88}$ Olsberg, et al., 14. 
The degree of intervention in the design for the Castelvecchio Museum ranges from modest to incursive. Ranging in scale and resolution, the drawings go from broad, colourful sketches of existing site surveys, room layouts, and window treatments to the most precisely drafted window and bracket details, roof construction, and building elevations. The drawings are intensely layered and dense with information. The fourteenth century fortified castle, which had been transformed into a military barracks by Napoleon during his occupation of Verona, was converted into a museum between 1924 and 1926 by the director of museums in Verona, Antonio Avena, and the architect Ferdinando Forlati. ${ }^{89}$ They had made superficial Gothic insertions in the courtyard façade of the old barracks and had modified the interior into an early Renaissance palace type. Scarpa's involvement began in 1956 with the appointment of a new museum director, Licisco Magagnato

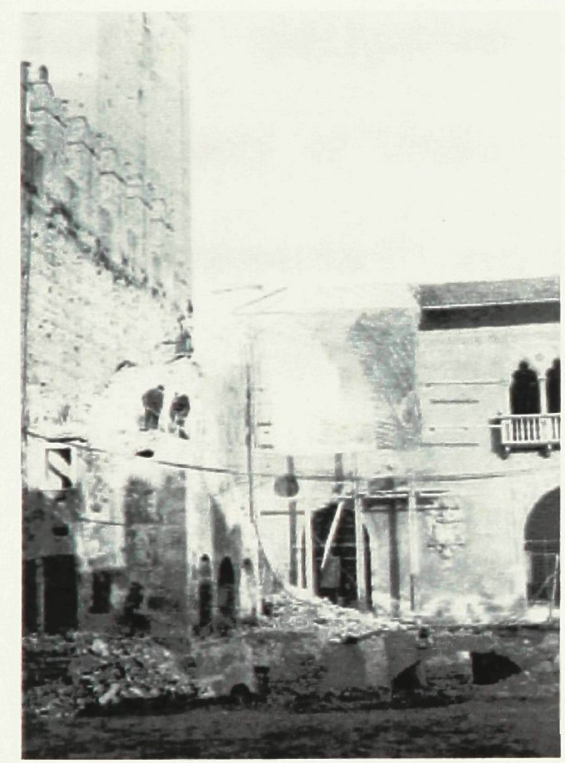

Fig. 13 - Demolotion of Napoleonic stair and continued for twenty years. ${ }^{90}$ Far more assertive in his approach, Scarpa carved out new spaces by cutting into existing fabric, repositioned the museum entrance, excavated the original moat around the Commune wall, remodeled the courtyard into a garden, designed new spaces and a new exit staircase, converted the east wing of the museum into offices, and, most significantly, demolished the
89 Olsberg, et al., 68.
90 Olsberg, et al., 68. 
"last bay of the gallery wing and the Napoleonic grand staircase". ${ }^{91}$ It is in this void that symbolism and architectural resolution combine to substantiate his ideas most legibly. In revealing the archeology of the existing structure, exposing elements of subsequent accretions, and in introducing a radically different formal vocabulary within this cut, Scarpa contradictorily makes "an articulate seam between many moments in time". ${ }^{92}$ The placement of the Cangrade della Scala statue within this space was a move that suffered many iterations and scrutiny. The statue, a commemoration of "one of the city's most distinguished rulers, descendants of whom constructed the Castelvecchio" ${ }^{\prime \prime 3}$, was deliberately

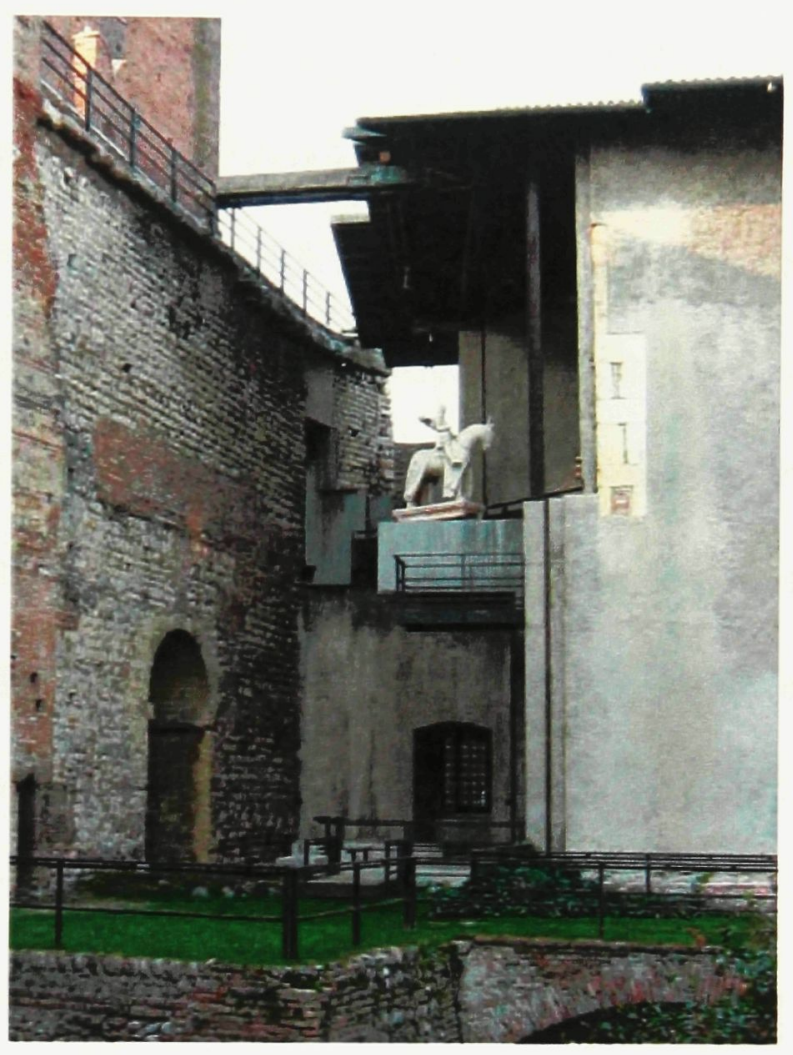

Fig. 14 - Castelvecchio Museum, Verona, Italy (1959-73). Area of excised bay of gallery wing.

made the focal point of the space as it is the converging point for historical moments as well as for several different circulation routes. The location of the statue, its position in space, the shape of the stand, and even the orientation of the statue on the stand were details that suffered exhaustive examination and reexamination. Because the placement of Cangrande was such a potent and pivotal

\footnotetext{
91 Olsberg, et al., 68.

92 Olsberg, et al., 70.

93 Olsberg, et al., 76.
} 
move, it was important to Scarpa that the statue be displayed a certain way making it observable from several different vantages.

Scarpa's explorations in devising a design are obsessively and painstakingly thorough. To have taken twenty years to complete a three-phase project should be evidence enough of this fact however further proof can be found in tracing the evolution of his design drawings and the decisions these helped him to make. For example, the innumerable sketches for the statue's stand accompanied by rough dimensions, roughed out connection details, and brief written explanations is very much like a thesis which undergoes countless corrections and revisions in narrowing toward a purified and succinct final product (see Fig. 15, page 54). The design for Castelvecchio is clearly responsive to the area outside the castle's fortified walls, to Verona and its history. It may be difficult to classify Scarpa's approach according to Hewitt's criteria for 'how to properly affect historic buildings' however there is no denying the communicability of the intervention as a new direction in the castle's history made true by the severity and confidence in Scarpa's surgical and archeological approach. If Scarpa's moves hadn't been so forceful and brazen, they might have lacked the oomph that they needed to be properly convincing. Despite the calculated precision of each decision and each detail, it's the architect's sensibilities and idiosyncrasies that infuse this structure with such energy. There is no guide and no analytical exercise that can lead to this particular solution. This is the element in developing an 'Ecology of Architecture' that is more difficult to quantify and to define. Room must be left for indeterminacy 
because it is in taking a leap of faith and trusting the architect's abilities that the potential for a meaningful architecture is created. Budgets can be estimated, a date of completion can be predicted, precise drawings can be flawlessly executed but there is the factor of the gestalt in architecture - the whole is more than the sum of its parts. Equal amounts of pragmatism and passion are essential qualities for an architect undertaking such an enterprise. 


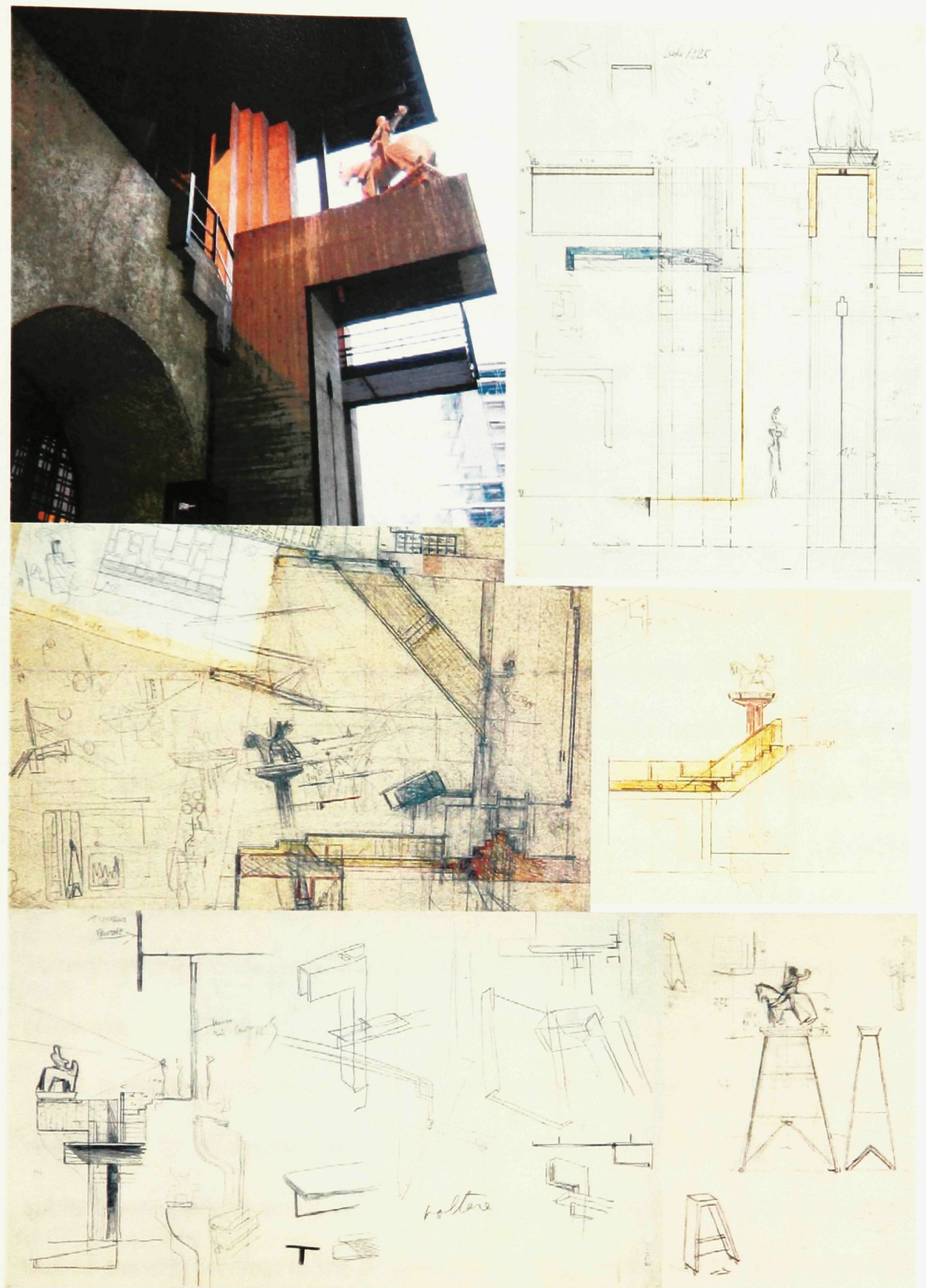

Fig. 15 - Detail studies demonstrating evolution of Cangrande statue's stand and configuration. 
In observing and evaluating Bern for the purpose of my studio project, I discovered that, despite a citywide consensus for uniformity, there existed a rebellious element in the population displeased enough to demonstrate publicly. One night, a mob of protestors noisily clambered down my street: Brunngasse. One man was chanting in German on a megaphone from the cab of a truck backed by blaring hip hop music and a group of extremely vocal pedestrian protestors who held banners and signs bearing their messages. Their voices resonated off the hard surfaces in the narrow corridor making for an intensely dramatic experience. In an open plaza called 'Waisenhausplatz', an area within view of our school, I witnessed on two separate occasions, a gathering of demonstrators who, armed with nothing more than a microphone and a tent, attracted much attention to their cause. In addition to public demonstration, another form of dissent that is much more ubiquitous and deplorable is the rash of graffiti in the city. At times very artful, the work produced by the underground adherents of this movement can sometimes only be viewed in the dark beneath highway overpasses and in daunting alleyways.

In response to these reactions to repression, I proposed an architectural intervention to be located in the Waisenhausplatz plaza which is the roof of a subterranean parking structure. 'The Living Museum of Contemporary Expression' was to stand in contrast to the immutability and inhumanity of the anachronistic city and provide a legitimate platform for evolving and dissonant forms of expression 
such as art (including graffiti), music, poetry, and political demonstration. The guiding concept, a contrast between permanence and impermanence, is embodied in the installation's materiality. Concrete is used as

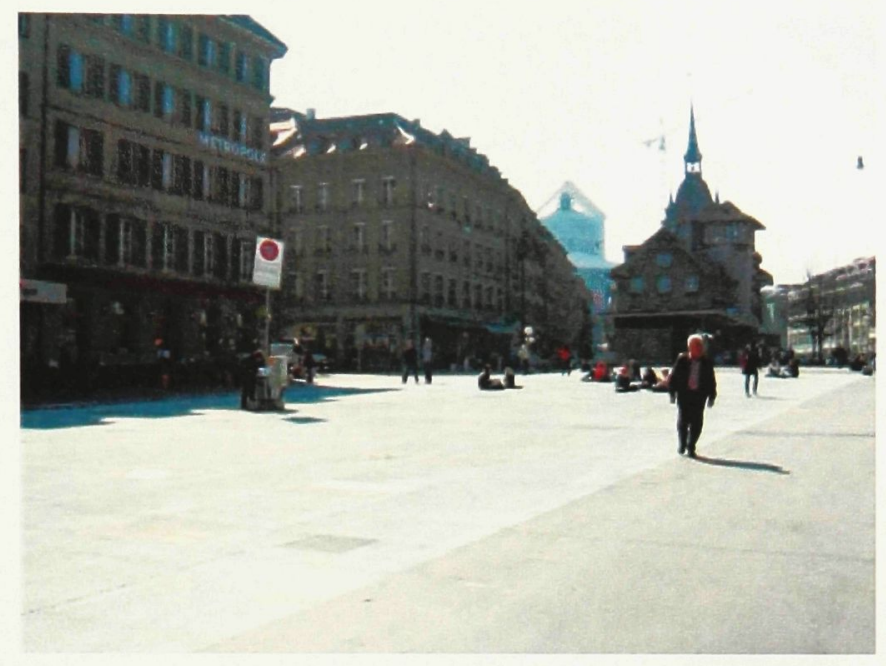

Fig. 16 - Waisenhausplatz the material for the main exhibition building and the graffiti art walls. The collapsible wooden structures correspond to the temporary exhibition space, the outdoor art studio, and the various seating arrangements on the site. By maintaining the ease of circulation through the plaza and by minimizing the amount of shadow cast by the installation, the aim was to preserve the kaleidoscopic nature of the site, a bare slab, and to enhance its function. By virtue of its ability to morph, transmit messages, to gather people for the intended purpose of its own defacement, the Living Museum resists the stagnation of dead history by providing a voice for new ideas, hopefully proving that a World Heritage City mustn't be merely a shrine to the past. In the midst of the mute stone buildings, a truly organic architecture will assert itself as belonging to a distinctly separate time. This idea was a worthy precursor in helping to establish the groundwork for the 'Ecology of Architecture'. 


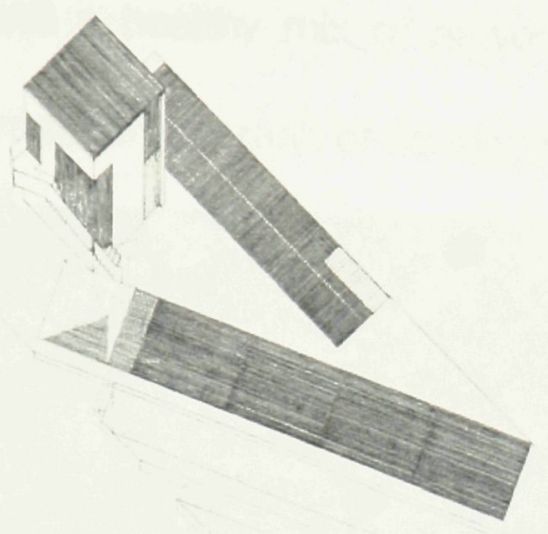

Fig. 17 - Closed Configuration

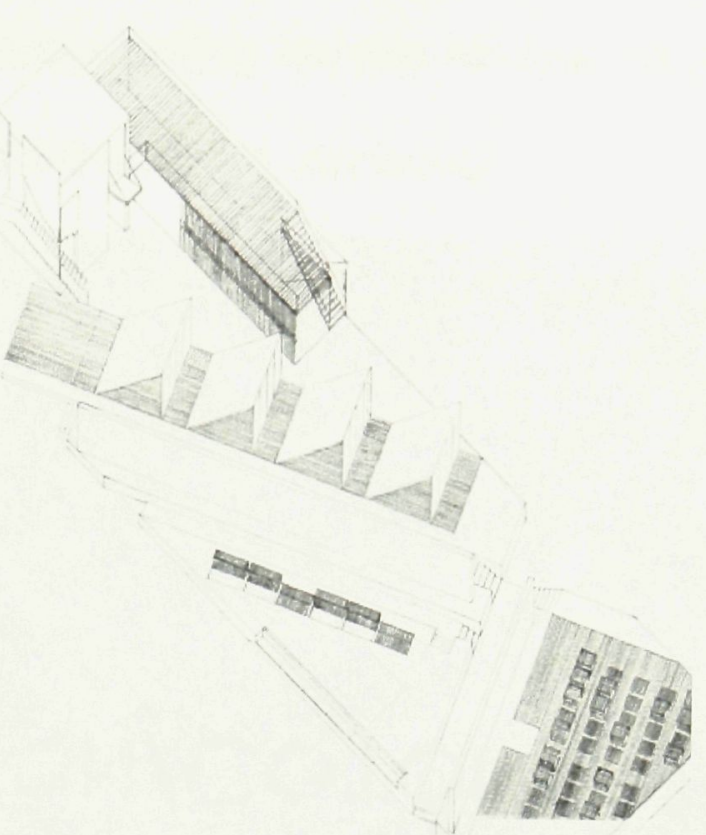

Fig. 18 - Open Configuration

St. Brigid's Church prominently fronts on three streets: Murray St., Cumberland St., and St. Patrick St. The rectory, a little red house, fronts on Murray St. The church is located on the eastern fringe of the ByWard Market area in a seedy section of town. The derelict Our Lady's School (1904) across the street from the

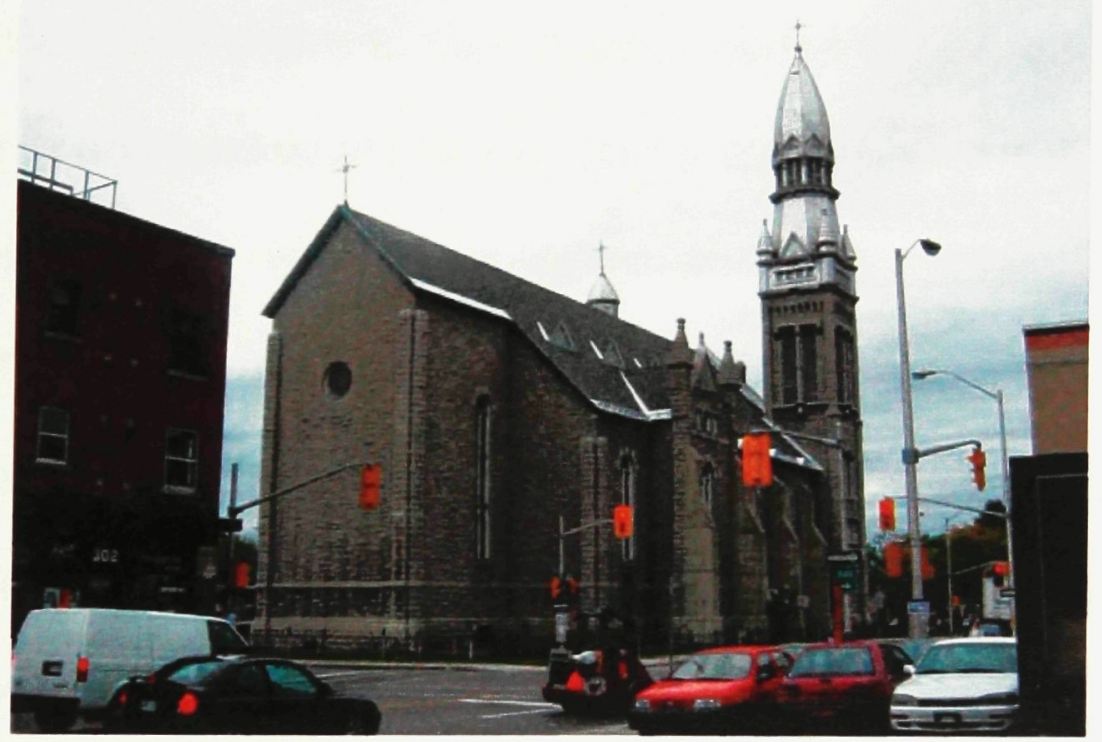

Fig. 19 - St. Brigid's Church, south-east corner

church stands as proof of the fate of many of Ottawa's older buildings. It appears to be on its last legs. Despite the evident decay occurring in this district, there is 
still a healthy mix of newer and more reputable looking low-rise housing not to mention the rash of condominium towers that are sprouting unchecked.

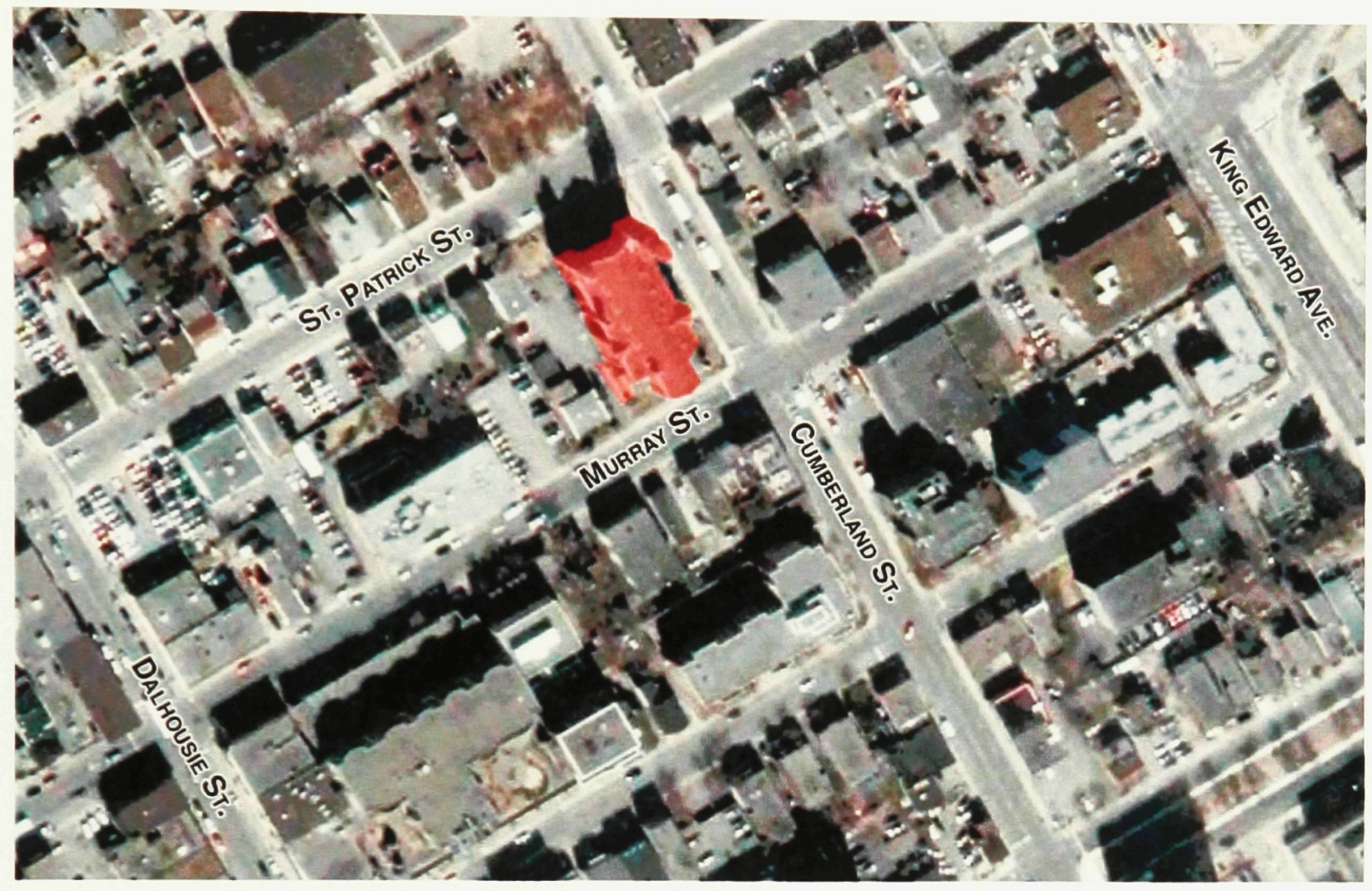

Fig. 20 - Aerial view of ByWard Market in area of St. Brigid's Church

From the exterior, the church seems to have stoically resisted the passage of time and reveals little of its one hundred and twenty years at first glance. A fairly recent and quite insensitive repair effort is, ironically, the most noticeably disagreeable thing about the church's current appearance. While repairing the roof, the workers carelessly allowed tar to stain several portions of the old stone exterior. More startling is a structural retrofit that consisted simply of grafting incongruous concrete buttresses to the existing stone structure. The interior of the modest church is wood for the most part: the columns are clad with a decorative wooden shell, the floors, vaults, the pews, and all ornament including the altar are wood. 
Featuring a classic, simplified Basilican plan, the nave is lofty and receives much natural light. The original paint has been painted over in white. The asymmetrical towers are unfinished on the inside and are havens for rodents and pigeons and are quite filthy. The towers are however the most apparent and recognizable features of the structure. They rise up to mark the church's presence in the Market lending some distinction to the area's increasingly uniform profile. In the larger context, the church belongs to what was formerly known as Lower Town. All of Ottawa's lower classes were relegated to this lower lying area. The area is now gentrified and is a bustling center for commerce and entertainment.

To a lesser degree, the phenomenon observed with the Theater of Marcellus in Rome is discernible in the Market. The original fabric has been pressured to suit the evolving nature of the place and the buildings are often crudely but effectively made to accommodate new uses. Thus, a physiotherapy clinic and a pizza vendor will occupy the same small building. Buildings whose parts are obviously of different vintages are commonplace. An old masonry home could have an aluminum siding growth filling out the maximum buildable space in a yard. It can be observed that several building types are repeated in the Market but they've endured and have all become uniquely identifiable each one with its own particular characteristics. If you had a friend visiting Ottawa for the first time, you'd take them to the Market on a Friday night as a way of introducing them to this city. A tourist attraction and a place of business, the Market is one of the few places in the city where pedestrians are undisputedly dominant. The Houses of Parliament, the 
National Art Gallery, the Rideau Canal, and Ottawa's business district are all only minutes away ensuring a steady flux of people in and out of the Market at almost any given time. Despite the presence of a certain number of homeless people, the downtown is quite safe.

Although it is common to see older buildings assume new uses, if my proposal for St. Brigid's were implemented, it would be the first time in the Market that an ecclesiastical building was transformed for a non-religious application. It's uncommon but entirely appropriate. It is this area's diversity that makes it so attractive. The church will house a business office, a residential living component, and a small grocery and food court primarily for the convenience of building residents. The design is intended to maximize site usage. The degree of intervention will be similar to that at Castelvecchio. Excisions, additions, penetrations, and grafts will be made to fit the new pattern of use. To exploit the structural and weathering qualities of the stone, it will be used in the construction of the new residential blocks extending from the existing building into the site. Although quarrying stone is energy intensive, the environmental impact is balanced by the sustainability that such structures achieve as was shown with the Theater of Marcellus. In observing the footprint of the church as a figure-ground drawing, the massive stone walls clearly delineate the form and emphasize structure. The structural lines were extended beyond the envelope into the site. The new stone walls follow these lines compliantly but are conspicuously at odds with the conventional plan. The new walls encircling the towers on the north side fuse into 
the existing walls in a way reminiscent of the Theatre of Marcellus so that this intervention won't easily be undone, marking a clearly defined point in the building's

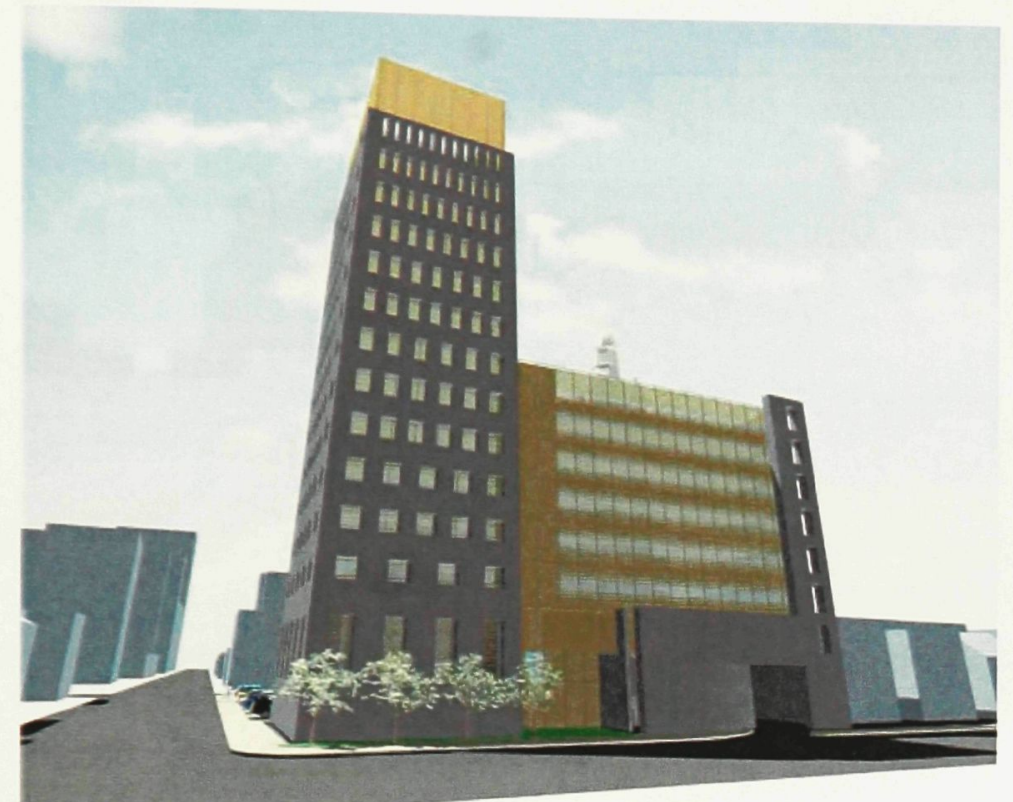

Fig. 21 - View of new façade on north side

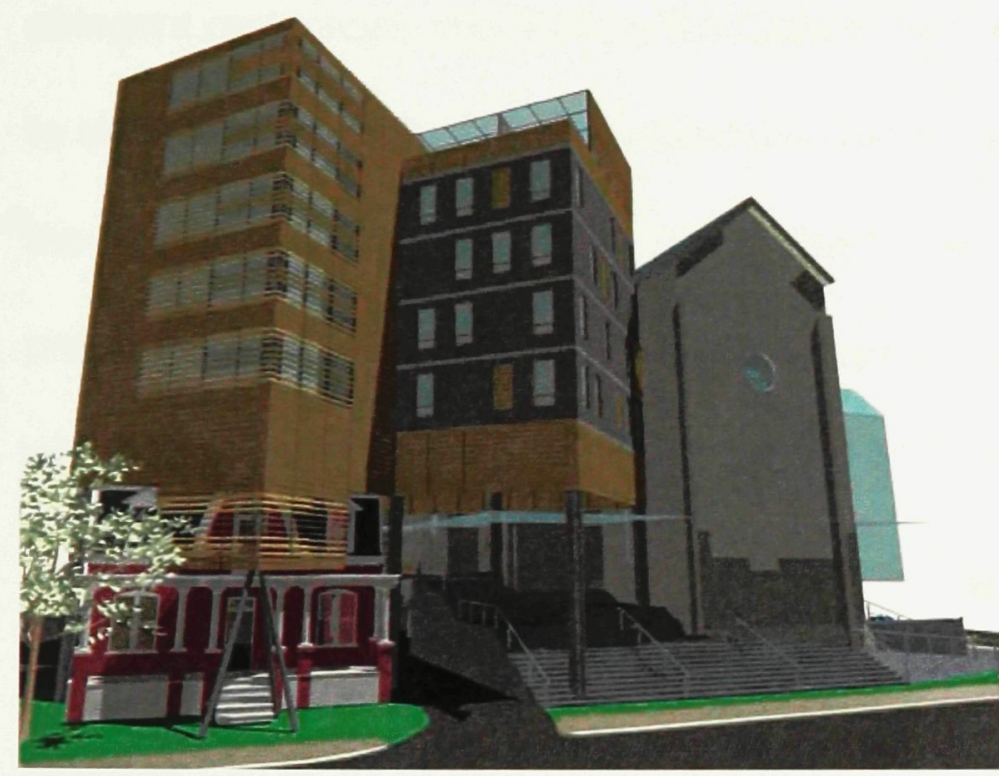

Fig. 22 - View of new façade on south side history. On the south side, a solid stair and ramp wrap around the building fused into its side transforming the south side into a new point of entry and thus changing its character from 'the rear end of the building' to 'another front'. The residential block on the south side hovers above the rectory using it as a ground level entry point. The block brings the church and the house into correspondence with each other uniting previously disparate elements belonging to a same site. The east

elevation fronting on Cumberland St. becomes a distinct front-facing façade as well as it is in this portion of the building that the office component will be housed. The 


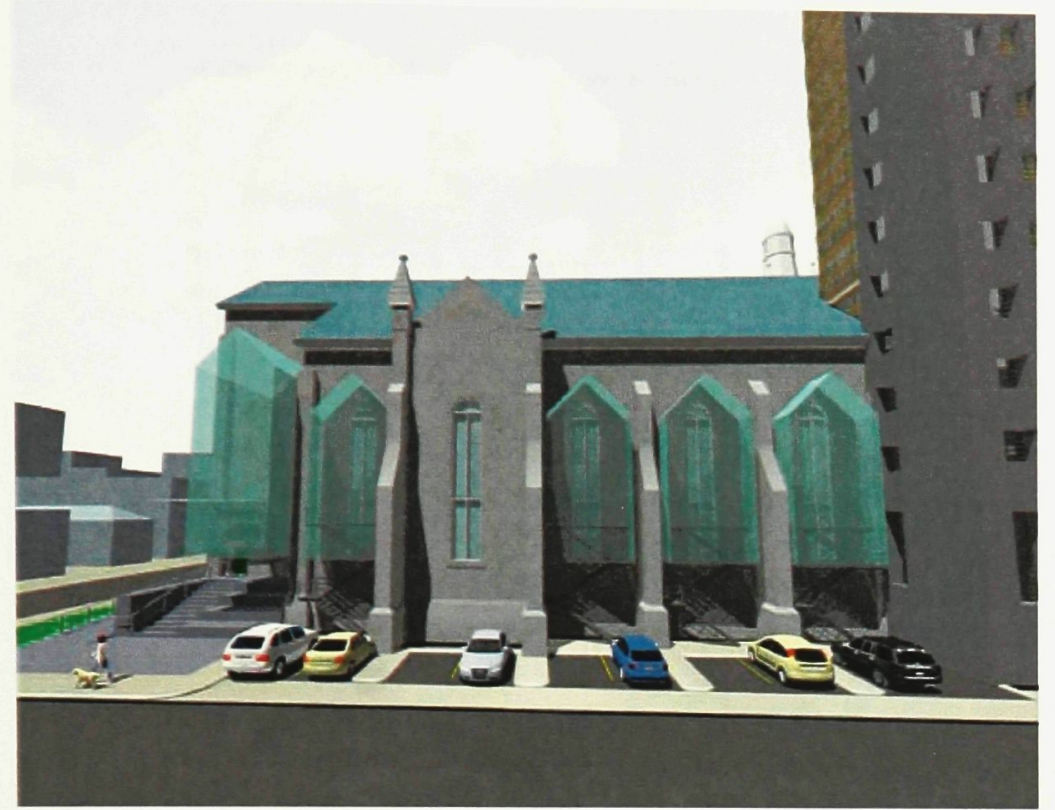

Fig. 23 - View of new façade on east side

office entrance, also on this façade, is a new opening coming into the former church's apse. It features an incorporated bus shelter.

The interior modifications are more delicate in part due to the much more fragile character of the original wood finishing but also due to the stringent restrictions imposed by the Ontario Heritage Foundation. It was my desire to show that a worthwhile architectural solution could be afforded that would satisfy the exigencies l've put forth in the thesis while also satisfying those of the preservationists. Some very minor surgery must be performed because, as previously mentioned, some pain must be accommodated in the birthing of these new uses. A custom steel skeleton designed to be as minimal as possible will be erected following the pre-established structural lines. Framing each column, the skeleton would be braced together hovering just above the pews avoiding contact with the existing fabric save for the vertical contact points with the floor. At this juncture, holes will need to be drilled through the floor to allow the columns to carry the forces down through the basement into the foundation. The skeleton will 

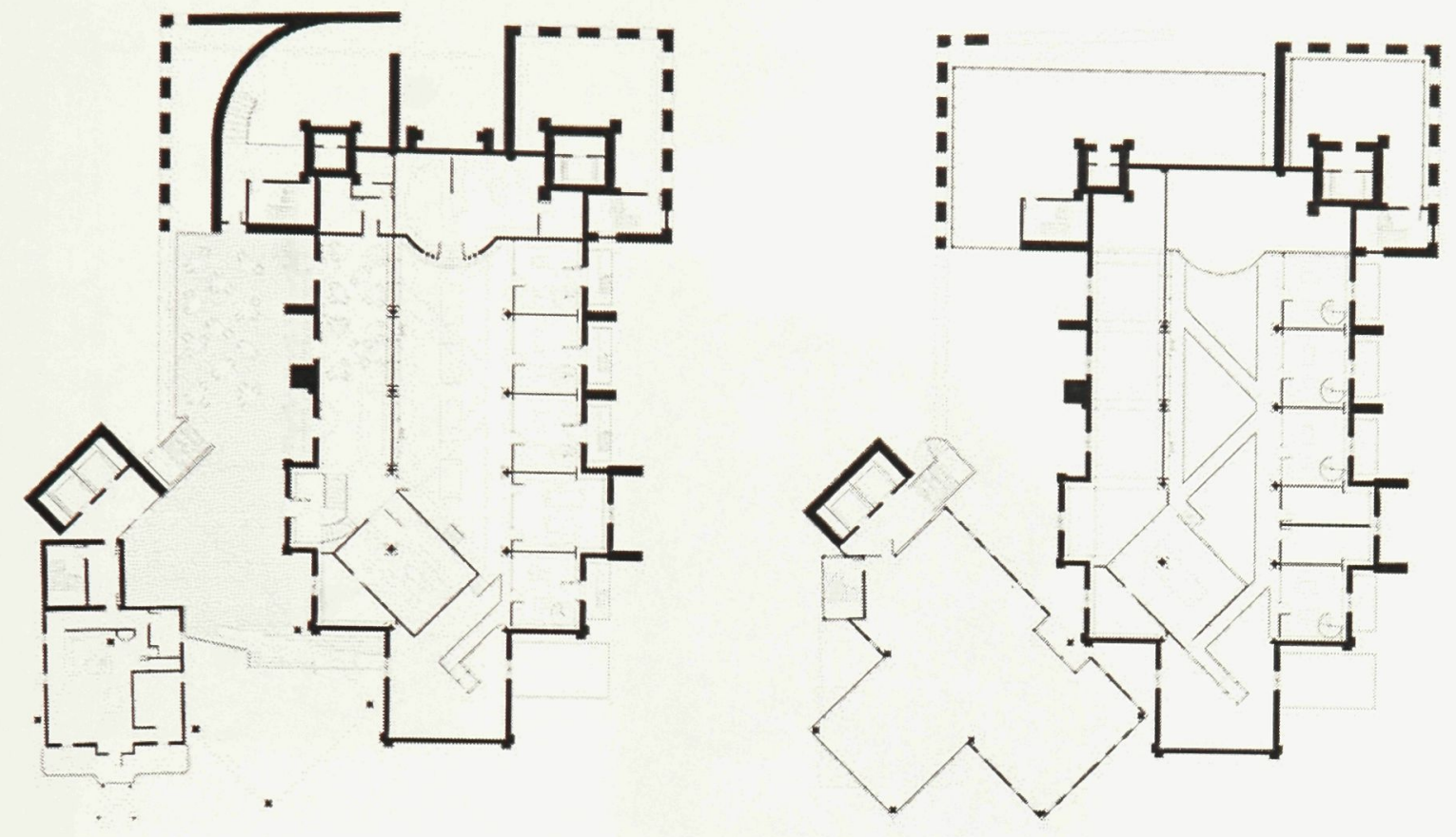

Sr. Furmak St.

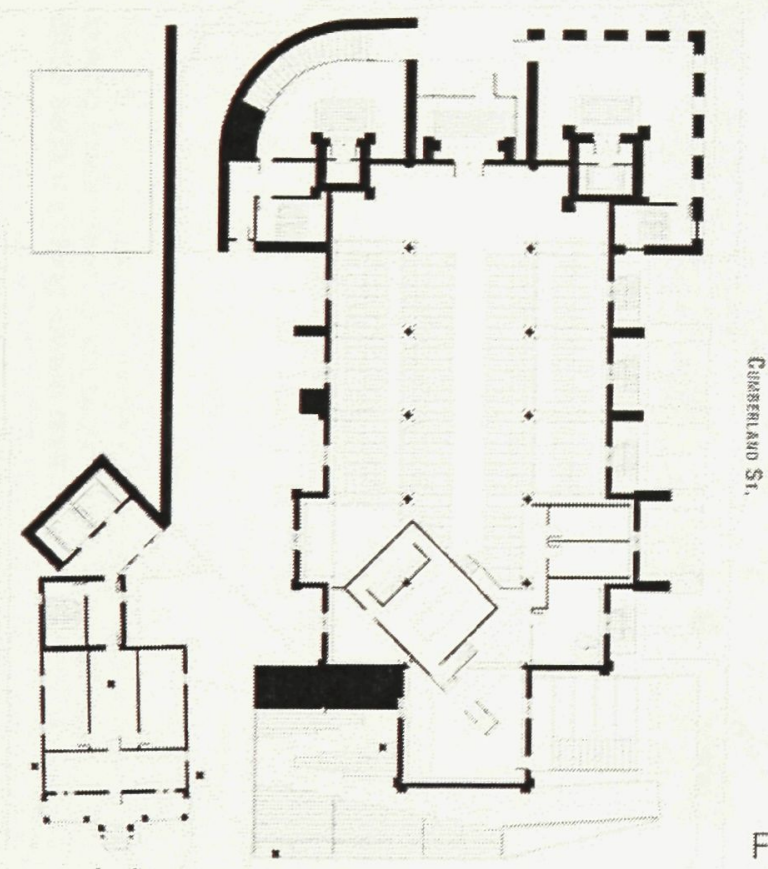

Fig. 24 - Clockwise from bottom left: ground floor plan, second floor plan, thrid floor plan. Plans are not to scale. 



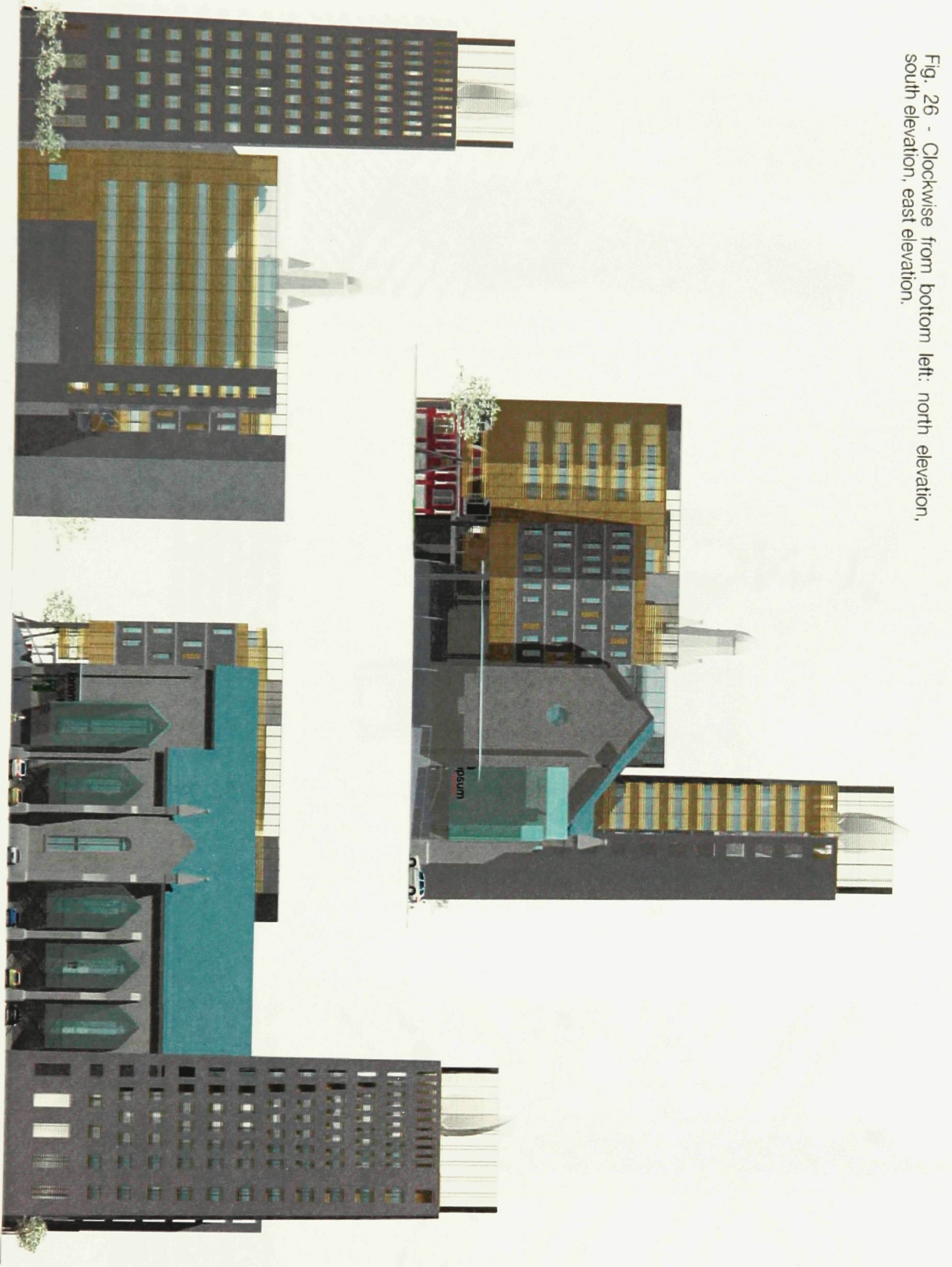




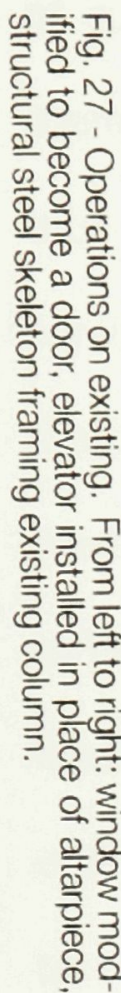
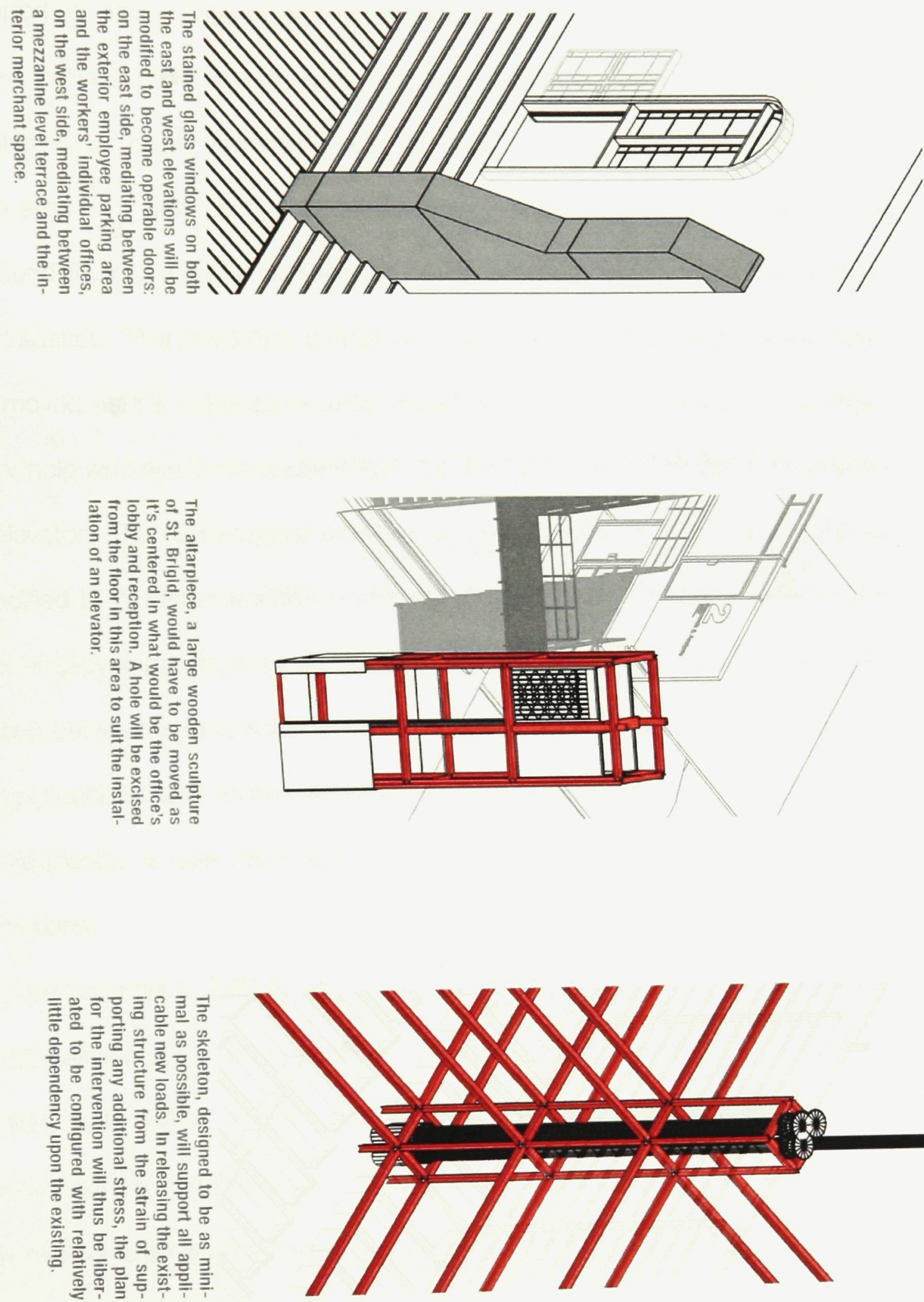
support all applicable new loads. In releasing the existing structure from the strain of supporting any additional stress, the plan for the intervention will thus be liberated to be configured with relatively little dependency upon the existing. We thus also avoid costly retrofitting and damage to the existing structure and a surefire argument with the Ontario Heritage Foundation. Rising two stories above the ground floor, the office workers will be up amongst the formerly inaccessible vaulted spaces. The altarpiece, a large wooden sculpture of St. Brigid, would have to be moved as it's centered in what would be the office's lobby and reception. Another hole will have to be excised from the floor in this area to suit the installation of an elevator. The stained glass windows on both the east and west elevations will be modified to become operable doors: on the east side, mediating between the exterior employee parking area and the workers' individual offices, on the west side, mediating between a mezzanine level terrace and the interior merchant space. The previously underutilized towers will now serve as elevator shafts to transport north block residents, a use most appropriate for these resource intensive, sturdy constructions.

The potential to fulfill the requirements of the Ecology of Architecture exists in the intervention at St. Brigid's Church. Ottawa, unlike Old Bern, is a modern city in a steady state of flux. Interest must be roused to awaken people to the potential of such an architectural intervention in lending the city distinction. Recognizability is directly related to a sense of belonging, which, as the Romans knew, is a boon to civic pride. The dull symmetry of the church's orientation in taking advantage of its 
triple frontage were targets for enhancing the building's presence. Each façade is unique in appearance and each one is accessed in a particular way which defeats the former 'one axis' nature of the Basilican plan. In reconfiguring how we see, access, and inhabit the former church, a design mechanism is created which isn't dependent upon formal platitudes for expression. Certain phenomena that are observable in the Market such as the grafting of alien additions, the reassignment of use, a single building possessing many uses, and the predominance of weathering materials provide subtler means of creating a dialogue with the past. By incorporating these phenomena and by not treating the church as a "venerated artifact" ${ }^{\prime 24}$, the potential is created for the structure to speak of the area beyond its property line. By framing a column clad in an ornamental wooden shell with an efficiently and elegantly engineered steel skeleton, two very distinct moments in time enter a "conspicuous dialectic" 95 where the past and the present are united in the interest of maintaining continuity. Without the benefit of being able to test this hypothesis with a built example and the necessary element of time, it's difficult to say conclusively that this experiment in re-conceiving preservation will result in a built work that coalesces within its historical setting. However, mindful of the dialogue of "what is there and what might be", the conditions are right for us to, as Scarpa suggested, trust time "to fuse it into a comfortable whole". ${ }^{97}$ Thus, a strategy is devised in which there is no one right way. Each architect following this

\footnotetext{
94 Hewitt, 198.

95 Olsberg, et al., 14.

96 Olsberg, et al., 14.

97 Olsberg, et al., 14.
} 
same strategy will make sense of the problem in his/her own way. Each project is free to be read any number of ways but each one is distinct from any other by its own particular set of characteristics and thus a solution cannot be replicated in differing circumstances as is observable in the sprawling exurban developments on Ottawa's periphery and the pastiche of bad historical reproductions in Ottawa's downtown area.

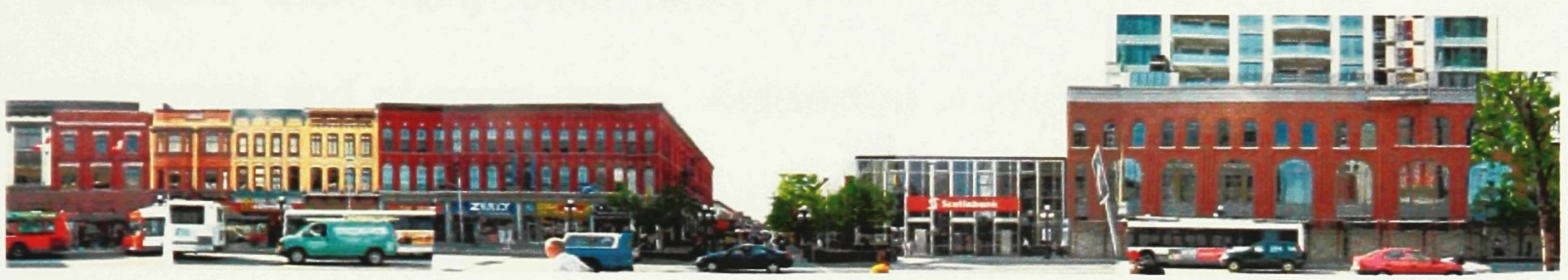

Fig. 28 - A stretch of Rideau St., Ottawa, Ontario. The condo tower (right) attempts to blend in to its historic setting. 
This investigation is strongly influenced by observations that have been honed by an education in architecture and by a particular perspective resulting from a Northern Ontario heritage and an internalization of both that landscape and that experience. The investigation prompted the realization that architecture is contingent upon many other factors in its role as shaper of the physical environment and of social order. Architecture is inextricably linked to the earth physically, to the weather its primordial opponent, to the climate in its dependence on energy, to history as a marker in time, and to people in its ability to express ideas and to grant a place distinction. Consequently, architects are ethically bound to consider the effects of their work beyond the property line. Their personal histories influence the way they perceive the world around them which is a tremendous responsibility in concretizing ideas about how people should live. As stewards of the built environment, it is incumbent upon them to be aware of the position architecture occupies relative to the other domains of life. In an architectural sense, 'ecology' is the interrelationship of buildings in space and time and the interactions, symbolic and literal, between these buildings and their environment which comprises the beings and factors in contact with them.

Irresponsible, profit-based development that ignores all other concerns is anathema to the Ecology of Architecture. Evidence: the city of Sudbury, where the health of the citizenry was secondary to economic prosperity. Evidence: the ByWard Market, where the profit motive of condominium developments supersedes 
the wellbeing of the very thing it exploits: the character of this historically significant area. A renovation of the type proposed in this thesis for the now decommissioned St. Brigid's Church would be an unprecedented leap for Ottawa in terms of its unconventionality. It would only take one precedent such as this one to open people's hearts and minds to the realization that their city's identity is more important than the irreversible sacrifice of its authentic fabric for condo towers that maximize lot occupancy and rentable space and the artificial and patronizing attempts by developers to pass these indelicate and feeble constructions off as worthy of belonging to a neighbourhood of such age and distinction. The falsity of styrofoam-shaped cornices and faux-brick façades fail to commingle with the veteran masonry buildings of Rideau Street and other prominent streets in the Market. Health in a city amounts to much more than a thriving economy.

Cities that lack integrity and the legislation to control irresponsible development like Ottawa and those who are burdened by tourism-based revenue and historical designation like Bern both treat architecture as a novelty and both are stunted in terms of their built histories. Confusion about identity is symptomatic of the disparity between the 'who and what we were', the 'who and what we are', and the 'who and what we'd like to be' in both capital cities. If the citizenry is excluded from input and participation in this decision, the result will be a feeling of further disaffection and marginalization. A city with a fluid history is one which fosters a sense of belonging and is thus, in terms of civic pride, a healthy city. A feeling of marginalization may also be attributed to the cities' stringent regulations for 
preservation that largely restrict the degree to which one is allowed to affect historically labeled fabric. 'Old' doesn't necessarily mean 'precious' and it also doesn't necessarily insinuate 'archaic'. The Romans' attitudes and methods regarding the treatment of their so-called historic buildings 1,600 years ago were more mature than current-day practice in North America. Their buildings, as opposed to the weather-ignorant confections of modernity, stand as mute testament to the durability of earthen materials. It is in the work of independents such as Aalto and Scarpa that we see unique expression rooted in provenance and the logic of design tradition and innovation and a reverence for materiality and time and thus also, a mindfulness for a building's lifespan and its ability to endure.

The design for St. Brigid's Church is an example of responsible development that doesn't exclude profit. It takes more than profit into consideration. In encouraging the reuse of this building, the environment is spared from suffering the burden of the costly and energy-intensive demolition and clearing of the existing structure and an historical monument assumes a new use within its original context thereby proving that a Heritage building may indeed continue to be a useful contributor and not merely an occupier of space. The perpetuation of the church's history would equate the salvation of not only a tangible record of the past but would signal, for the city of Ottawa, an initiative in resisting the onslaught of rampant condo development and a step in actively curbing the alarming trend of the slow erasure of its unique identity inviting the possibility for alternative strategies. 
The design itself, a hybrid of old and new, subtly borrows hints from its surrounding neighbourhood as acknowledgment of the 'who and what we've evolved to be' and seeks to assert itself so that it may, at once, sit comfortably amongst its quiet predecessors but also speak of the 'who and what we will be'. Like the work of Aalto and Scarpa, proffering a counterpoint to a well-established movement as a critical commentary serves to create precedents to suggest possibilities for how we may differently envision a solution. All of this has been to answer the questions: 'Why should we keep this building' and 'What should we do with this building'. The Ecology of Architecture answers these questions from a philosophical perspective as well as from a pragmatic and practical perspective; a way of thinking with a three-dimensional corollary. Through this lens, I have formed a foundation on which to begin to build an ideology, one that is intended to transcend fashion and style to become a part of architectural decorum. This idea will be reinforced and enriched in reporting each new solution devised with these principles in mind. Each solution will inform the next but only indirectly. Each solution will be an exercise in imagination in trying to unite a vision with a reality. One lesson in my education in architecture that is solidly instilled is to explore a worthy idea to its fullest extent. With at least one foot firmly rooted in reason, any idea can become a suitable design or even a progressive innovation in imaginatively reconceiving the possibilities for how we live. It would be a shame if St. Brigid's Church were to fall but it would also be a shame to leave the bell tower to the pigeons and the rats. 
Bibliography

Alchermes, Joseph. "Spolia in Roman Cities of the Late Empire: Legislative Rationales and Architectural Reuse." Dumbarton Oaks Papers, Vol. 48 1994: 167-178.

"Alex Haley Quotes." 2007. UBR Inc. 5 August 2008. $<$ http://www.people.ubr.com/authors/by-first-name/a/alex-haley/alex-haley-quotes.aspx>.

Bradley, Bill. "Digging Through the Sudbury Soils Study." Northern Life 29 May, 2008: 3-4.

"Development in the Greenbelt." June 2008. City of Ottawa. 28 July 2008. $\leq$ http://www.ottawa.ca/residents/public consult/beyond 2020/papers/greenbelt white pa per/index en.html>.

Dobbins, Michael. "The Achievement of Finnish Architecture: Social Responsibility and Architectural Integrity." Perspecta, Vol. 8 1963: 3-36.

Fixler, David N. "The Renovation of Baker House at MIT: Modernism, Materiality, and the Factor of Intent in Preservation." APT Bulletin, Vol. 32, No. 2/3 2001: 3-11.

Ford, Edward R. The Details of Modern Architecture - Volume 2: 1928 to 1988. Cambridge, Massachusetts: Massachusetts Institute of Technology, 1996.

Gibson, Timothy A., and Mark Lowes. Urban Communication: Production, Text, Context. Lanham, Maryland: Rowman \& Littlefield Publishers, Inc., 2007.

Glacken, Clarence J. Traces On the Rhodian Shore. Los Angeles, California: University of California Press, 1967.

Hewitt, Mark Alan. "Architecture for a Contingent Environment." Journal of Architectural Education, Vol. 47, No. 4 1994: 197-209.

Hilowitz, Janet Eve. Switzerland In Perspective. Westport, Connecticut: Greenwood Press, 1990.

"Human Health Risk Assessment Results." May 2008. Sudbury Soils Study. 28 July 2008 <http://www. sudburysoilsstudy.com/EN/media/handouts/SSS HHRA ENG.pdf>.

Leatherbarrow, David, and Mohsen Mostafavi. "On Weathering: A New Surface Out of the Tracks of Time." Daidalos, Vol. 43 1992: 116-123.

Leatherbarrow, David, and Mohsen Mostafavi. On Weathering: The Life of Buildings In Time. Cambridge, Massachusetts: Massachusetts Institute of Technology, 1993.

Monbiot, George. Heat: How To Stop The Planet From Burning. Canada: Doubleday Canada, 2006.

Murphy, Kevin D. "The Villa Savoye and the Modernist Historic Monument." The Journal of the Society of Architectural Historians, Vol. 61, No. 1 Mar. 2002: 68-89.

Olsberg, Nicholas, et al. Carlo Scarpa Architect: Intervening With History. New York, New York: The Monacelli Press, Inc., 1999. 
Peers, John, and Gordon Bennett. 1,001 Logical Laws, Accurate Axioms, Profound Principles, Trusty Truisms, Homey Homilies, Colorful Corollaries, Quotable Quotes and Rambunctious Ruminations for All Walks of Life. New York, New York: Fawcett Gold Medal, 1979.

Schumacher, E.F. Small is Beautiful: Economics as if People Mattered. New York: Harper \& Row Publishers, 1973.

Sear, Frank. Roman Theatres: An Architectural Study. New York, New York: Oxford University Press Inc., 2006. 